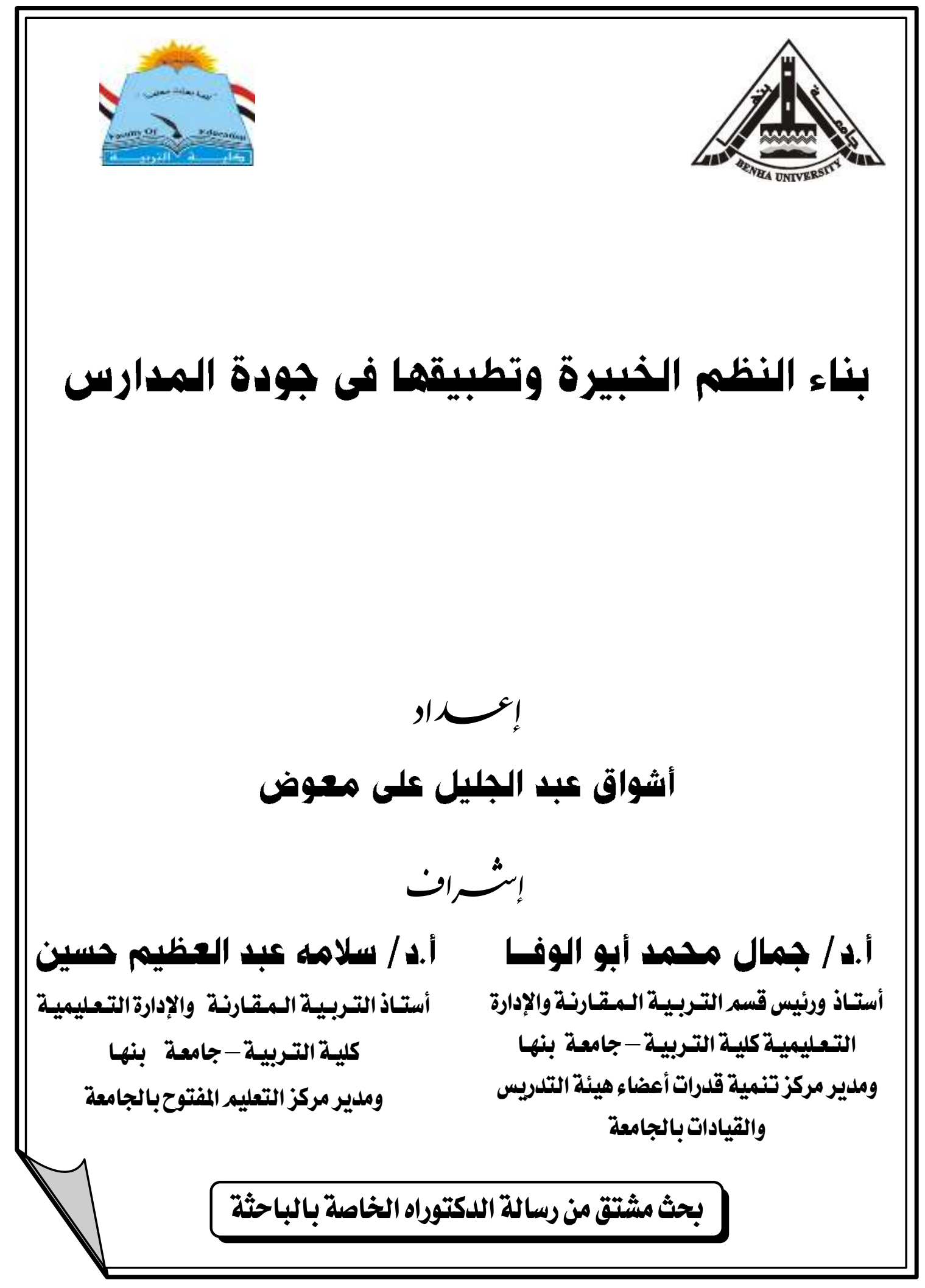




\title{
بناء النظم الخبيرة وتطبيقها فى جودة المدارس
}

\author{
! إن \\ أشواق عبد الجليل على معوض \\ إن
}

\section{أ.د / جمال محمد أبو الوفها أ.د/ سلامه كبد العظيم دسين}

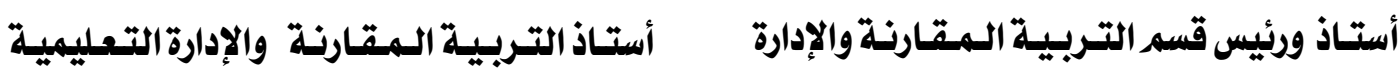

كلية التربية-جامعة بنها

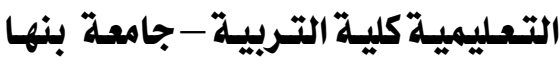

ومدير مركز التعليه المفتوح بالجامعة بهائ

وملدير مركز تنمية قدرات أعضاء هيئة التدريس بئسيا

والقيادات بالجامعة

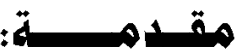

تعد تكنولوجيا المعلومات والاتصـالات من أبرز مظاهر التغيير في المجتمع، حيث

أصبحت تكنولوجيا المعلومات والحاسبات وتطبيقاتها المتنوعة مستخدمة في مجال التعليم حيث أصبحت تؤثر عليه تأثيراً كبيراً، ودعت كل القائمين على التعليم إلى نقل المعرفـة ودمـج

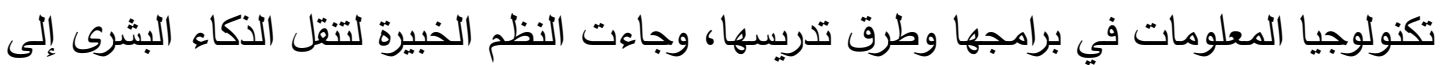
نظم الحاسبات عن طريق تصميم البرمجيات وأجهزة الحاسبات التي تحاكى سلوك وتفكير البشر، ولذا فإن النظم الخبيرة تحتفظ بمعارف متراكمة لأكثر من خبير ويجعلها جاهزة علي

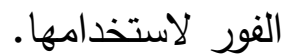

وكان لانتثار الحاسبات الالكترونية وتطور شبكات المعلومات المحلية والعالمية دور

فعال وأساسي في تطوير واستخدام النظم الخبيرة (')، ولذلك فإن تشابك وتداخل الخدات فروع المعات المعرفة

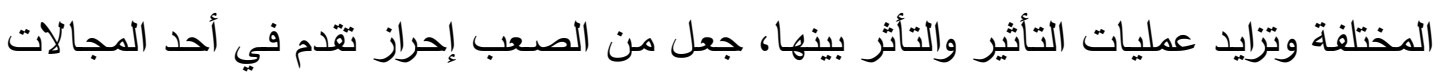

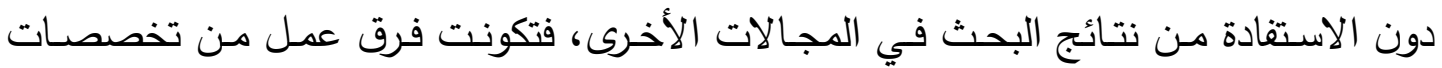
مختلفة لممارسة الأبحاث التعددية والابتكار الجماعي وأصبح من الطبيعي أن تجد علماء التربية

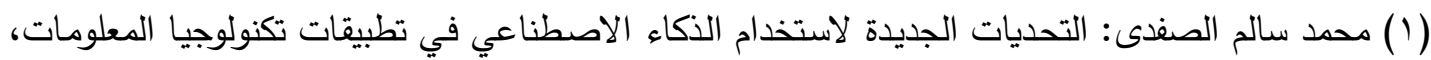

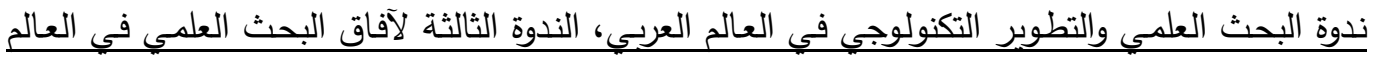

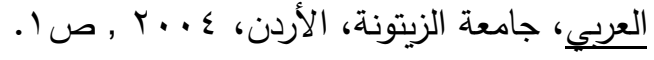


والهندسة والعلوم الإنسانية والحاسب الآلي يعملون كفريق واحد لتصميم منتج ما، ولقد كان الحل

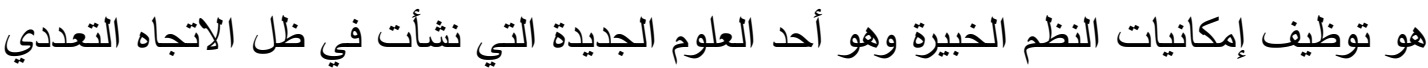

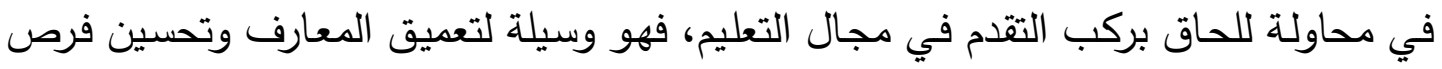
اتخاذ القرار (').

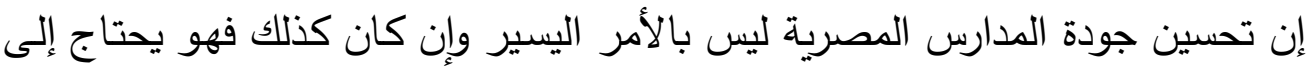

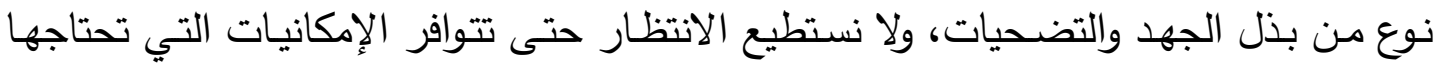

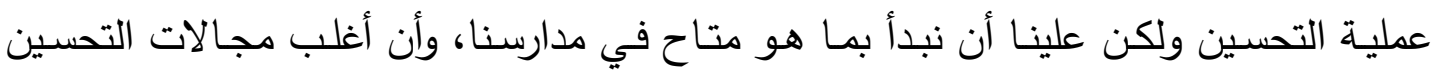

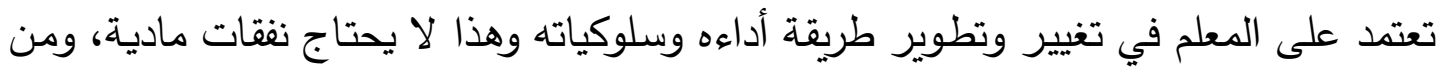

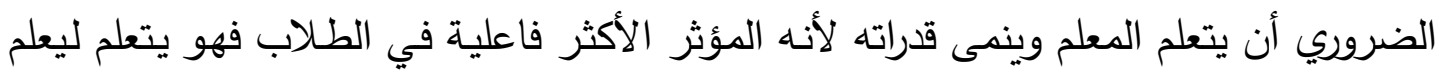

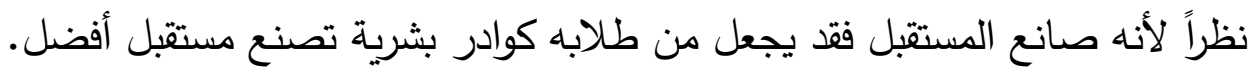

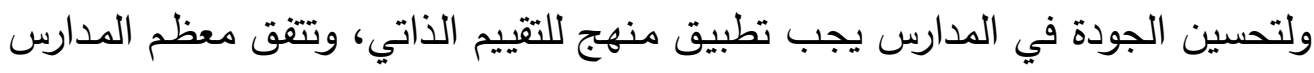

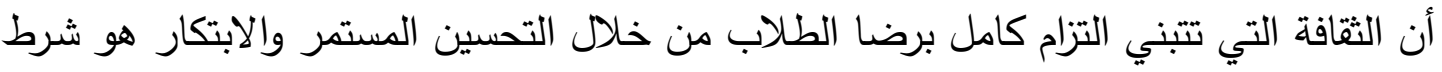

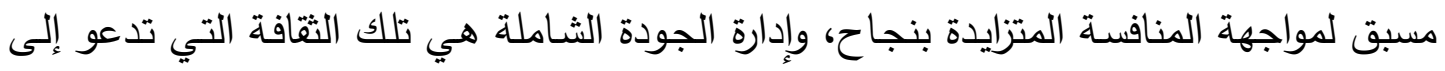

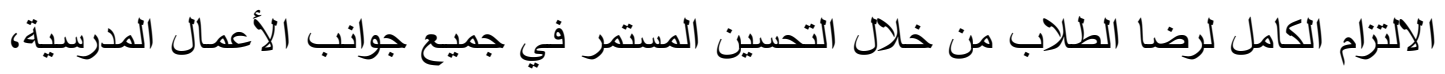

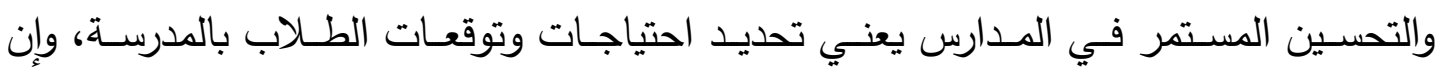

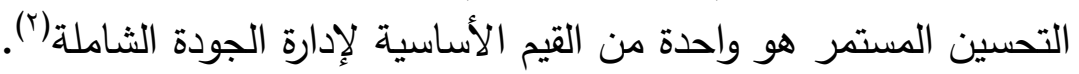

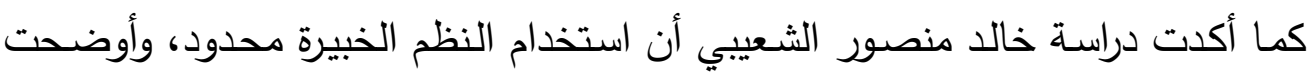

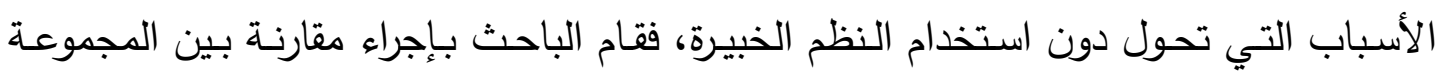

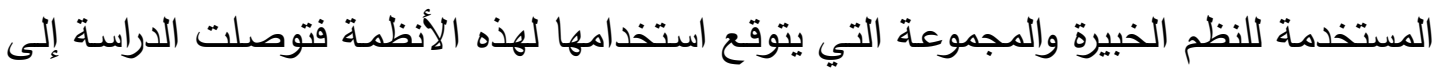

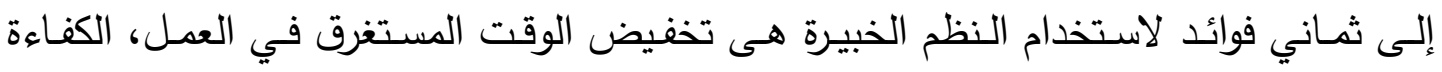

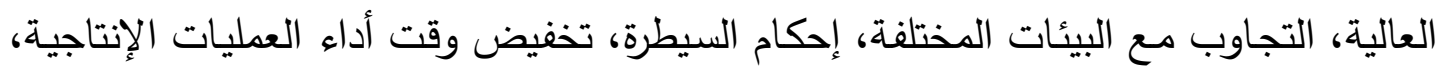
تخفيض حالات توقف العمل، التنظيم الداخلي للمؤسسة، واختيار الأساليب المناسبة (†).

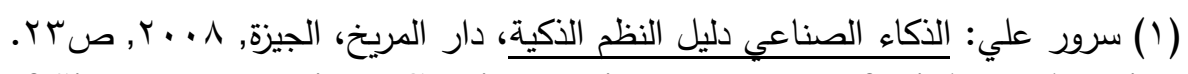

(2) Abdul Raouf Sitara - e - Imtiaz : Continuous improvement of Higher Education Quality, International Conference on Assessing Quality in Higher Education, $1^{\text {st }}$ $-3^{\text {rd }}$ December, Lahore - Pakistan, 2008, P.287.

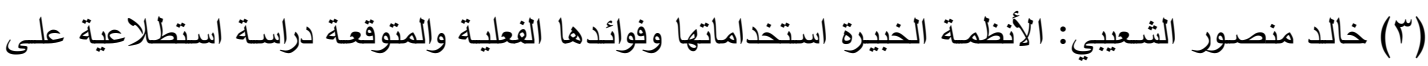

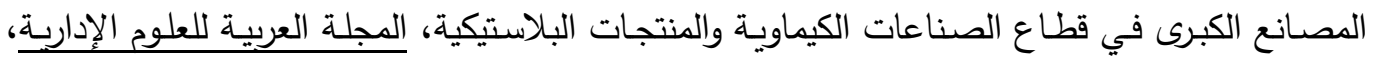

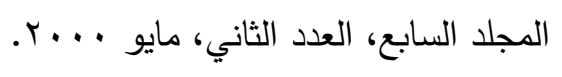


ومن أهم الدوافع التي تدفع إلى بناء النظم الخبيرة هي أنها تهدف لمحاكاة الإنسان فكراً وأسلوباً، ولإثارة أفكار جديدة تؤدي إلى الابتكار، وأن النظام الخبير يحتفظ بمعارف متراكمة لأكثر

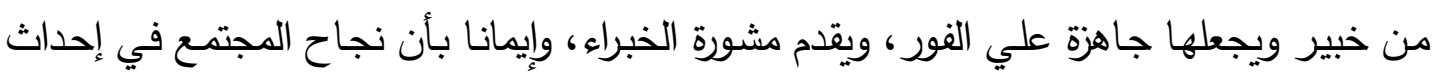

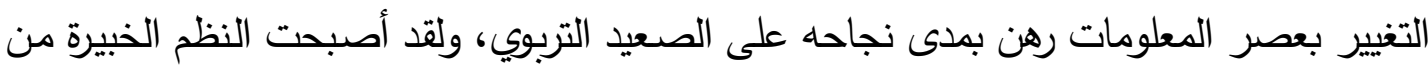

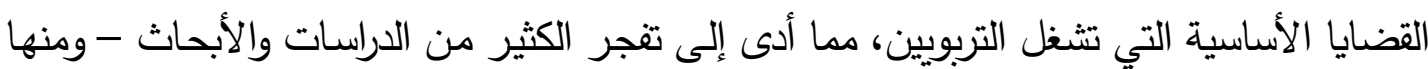
البحث الحالي - الذي يبحث في بناء النظم الخبيرة وتطبيقها فى جودة المدارس.

مشكلــة البحسث:

لقد أصبحت النظم الخبيرة من الضروريات الأساسية لمواجهة التحديات التى يفرضها تطور تكنولوجيا المعلومات، وإن المدارس تعمل على الاستفادة من كل ما توصل إليه العلم الحديث لمواجهة ما يعترضها من مشكلات تتظيمية وتربوية لتتسم بالجودة وتكون قادرة على التى

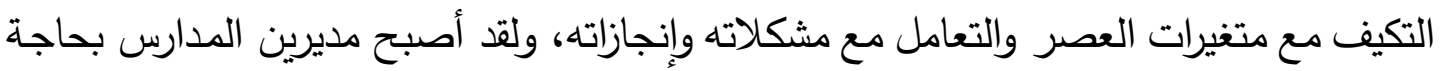

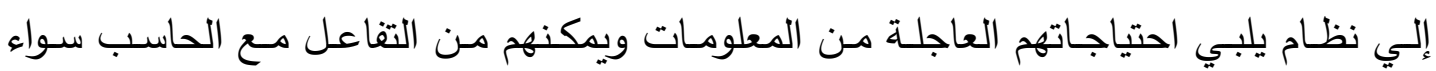
بإدخال متغيرات جديدة أو إجراء تغيرات لإدخال الجودة بمدارسهر.

ولذا يُعد بناء النظم الخبيرة وتطبيقها فى جودة المدارس ضرورة حتمية لتطوير النظم التربوية إنية والتعليمية في ظل المستحدثات العصرية، وذلك بعد ظهور مفاهيم جديدة تدعو إلى زيادة الاعتماد على تقنيات الكمبيوتر في التعليم، وبالنظر إلى الددار المصرية نجدها تواجه مجموعة من الصعوبات المتعلقة بتطبيق الجودة بها، لذا كانت الحاجة ماسة لإجراء بحث في هذا المجال للتعرف على كيفية بناء النظم الخبيرة وتطبيقها فى جودة الددار، ومن هنا تبرز التساؤلات التالية:

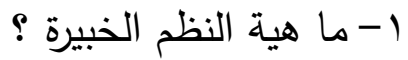

r- ما هى المكونات الرئيسية لبناء النظم الخبيرة ؟ النهاء

r- ما هى مميزات ومشكلات النظم الخبيرة ؟

ع- ما هى آلية عمل النظم الخبيرة وتطبيقها فى جودة المدارس؟

سعى البحث الحالي إلى تحقيق الأهداف التالية:

1-توضيح ما هية النظم الخبيرة.

r- التعرف علي المكونات الرئيسية لبناء النظم الخبيرة.

ب- الوقوف على أهم مميزات ومشكلات النظم الخبيرة.

ع - دراسة آلية عمل النظم الخبيرة وتطبيقها فى جودة الددارس. 


\section{نبعت أهمية البحث الحالى من الأمور التالية:}

1- قدم البحث طريقة غير تقليدية تناولت بناء النظم الخبيرة وتطبيقها فى جودة المدارس.

r- يبرز أهم الأسس النظرية للنظم الخبيرة.

ץ- ندرة الدراسات العربية التى تتاولت النظم الخبيرة.

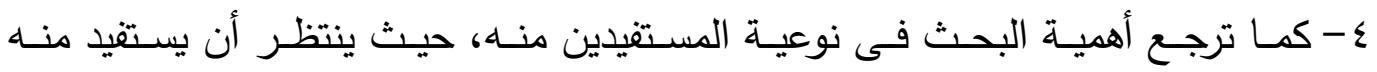

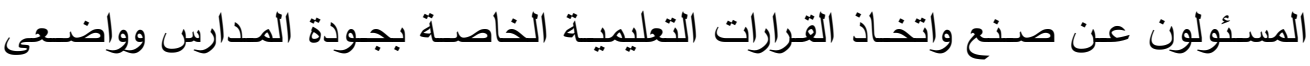

السياسات والإجراءات اللازمة لتطبيق النظم الخبيرة.

0- يمثل هذا البحث محاولة جادة لتوجيه الباحثين لإجراء المزيد من البحوث حول موضوع

النظم الخبيرة وتطبيقها فى جودة المدارس.

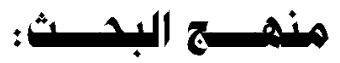

اعتمد البحث الحالي على المنهج الوصفى وهو المنهج الذي لا يقف عند حد الوصف للنظم أو الظواهر بل يتعدى ذلك محاولة التفسير والتحليل في ضوء القوى والعوامل الثقافية ليشخص الواقع الخاص بالظاهرة قيد الدراسة، وليكثف عن جوانبها وأبعادها الختلفة وتحديد العلاقات بين عناصرها، كما تناول البحث كيفية بناء النظم الخبيرة وتطبيقها فى جودة الددارس.

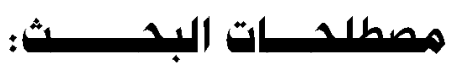

ارتكز البحث الحالى على المصطلحات التالية:

1. النظام الخبير(Expert System): وهو برنامج الكمبيوتر الذي يحتوي علي الكثير من المعلومات التي يملكها خبير في حقل معين من حقول المعرفة ويقوم على استخدام قاعدة المعرفة وخطوات الاستدلال وقوانين التفكير والمنطق للوصول إلي حل للمشكلات الصعبة

$$
\text { التي تحتاج في حلها إلى استشارة الخبراء. }
$$

r. مفهوم جودة التعليم (Quality in Education): إن الجودة في التعليم عملية بنائية تهدف إلى تحسين المنتج النهائي، وهى تستند إلى الإحساس العام للحكم على الأشياء،

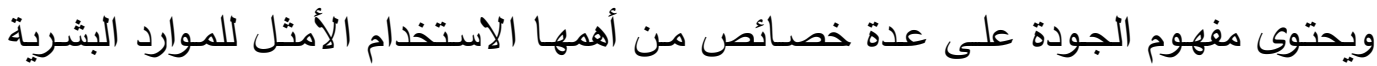
وخض التكلفة من أجل زيادة الطلب، وأداء العمل بالثكل الصحيح من أول مرة، وتقديم 
الخدمة بصورة تشبع احتياجات الأفراد، ووضـع بعض المعايير لقيـاس الأداء ومعنويـات

أفضل للعاملين (')

\section{الـراســات السـابقة}

توجد مجموعة من الدراسات والبحوث العربية والأجنبية ذات الصلة بموضوع الدراسـة

$$
\text { والتى يمكن تتاولها على النحو التالي: }
$$

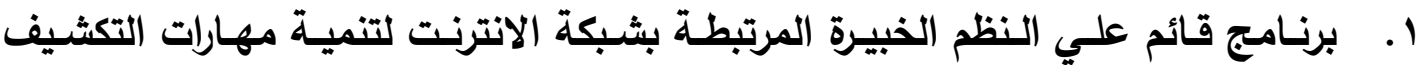

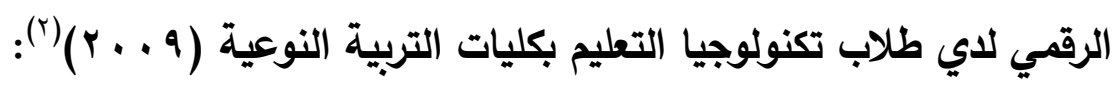

تهدف الدراسة إلي التعرف علي أسس ومواصفات البرنامج المعد بالنظام الخبير لتنمية مهارات التكشيف الرقمي المرتبطة بشبكة الانترنت، والتعرف علي أثر استخدام نظام خبير علي التحصيل المعرفي لمهـارات التكثـيف الرقمسي المرتبطـة بشبكة الانترنت في مقابـل الطـرق التقليدية، وقد استخدت الباحثة المنهج الوصفي والمنهجي التجريبي، وقد استعانت ببطاقـة ملاحظـة لتحديد المهارات الثـائعة في التكثـيف الرقـي المرتبطـة بشبكة الانترنت وبطاقـة ملاحظة لرأي القائمين علي تدريس الجانب التطبيقي وبطاقة ملاحظة الأداء المهاري للطلاب. وقد توصلت هذه الدراسة إلي أنه توجد فروق ذات دلالة احصـائية بين متوسطي أداء طلاب المجموعة التجريبية وطلاب المجموعـة الضـابطة في نتائج بطاقة الملاحظة لجميع مهارات التكثيف الرقمي للطلاب بعد التجريب لصـالح المجموعة التجريبية، وقد أوصت الدراسة باستخدام البرنامج القائم علي النظم الخبيرة المرتبطة بشبكة الانترنت الذي تم تصميمه في تدريب طلاب تكنولوجيا التعليم علي مهارات التكثيف الرقمي، كما أوصت بتصـميم وتطوير بـرامج قائهـة علـي النظم الخبيـرة المرتبطـة بشـبكة الانترنت للمقررات التعليمية بالتعليم العام والجامعي.

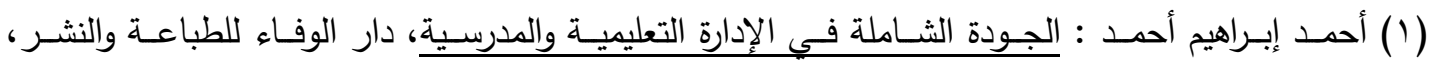

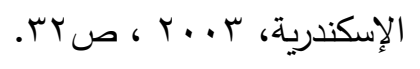

(r) نهير طه حسن: برنامج قائم علي النظم الخبيرة المرتبطة بشبكة الانترنت لتنمية مهارات التكثيف الرقدي

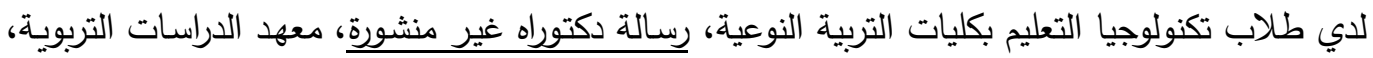

$$
\text { جامعة القاهرة، 9. . r. }
$$


تشـابهت هذه الدراسـة مـع البحث الحالى فى اهتمامها بموضوع النظم الخبيرة فى حين

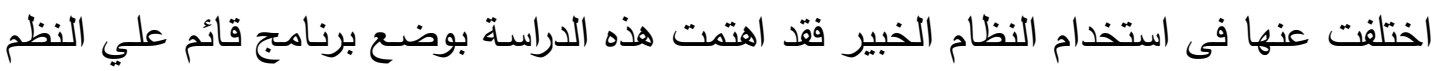
الخبيرة المرتبطة بشبكة الانترنت لتنمية مهارات التكشيف الرقمي لدي طلاب تكنولوجيا التعليم بكليات التربية النوعية، بينما سعى البحث الحالى إلى تناول كيفية بناء النظم الخبيرة وتطبيقها فى جودة المدارس.

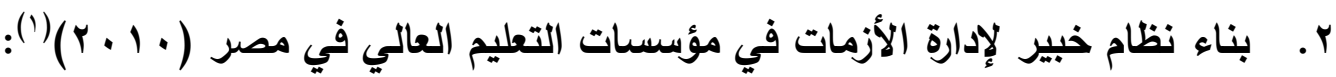

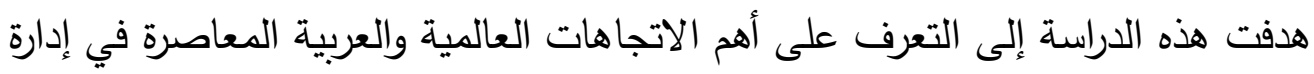

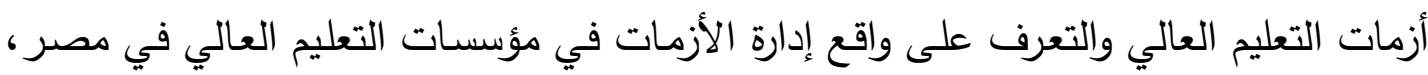

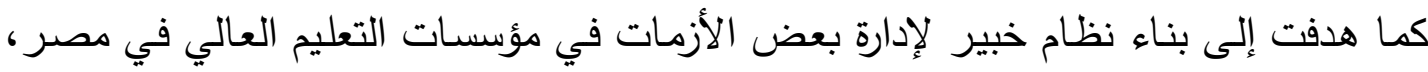
وقد استخدمت الباحثة استبيان أول لمعرفة الأزمات التي تواجها مؤسسـات التعليم العالي في لإني مصر ، واستخدمت الباحثة نظام خبير لإدارة بعض الأزمات التي تواجه مؤسسات التعليم العالي في مصر ، كما استخدمت استبيان ثان لمعرفة الفروق بين استخدام النظام الخبير المقترح لإدارة

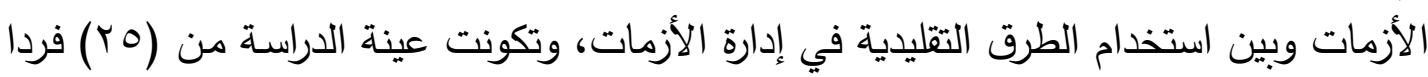

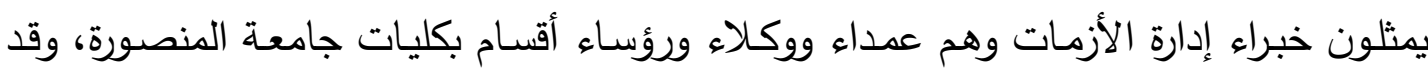

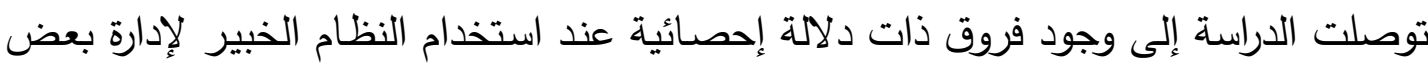

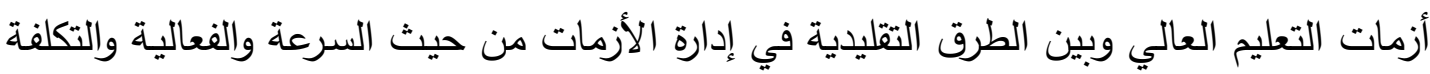

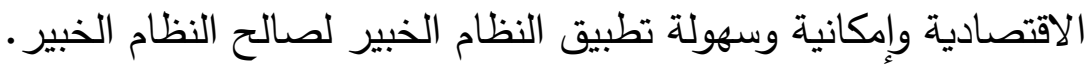
تشابهت هذه الدراسـة مـع البحث الحالى فى اهتمامها بموضوع النظم الخبيرة فى حين اختلفت عنها فى نوعية استخدام النظام الخبير فقد اهتمت هذه الدراسة بوضع نظام خبير مقترح

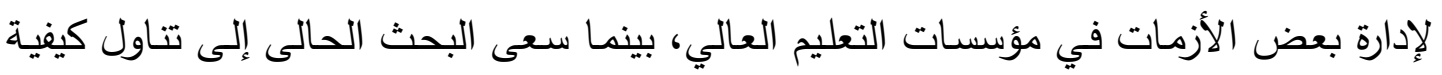
بناء النظم الخبيرة وتطبيقها فى جودة المدارس. r. تصميم نظام خبير لتنمية مهارات التعلم المنظم ذاتيا لدي طلاب إعداد معلم الحاسب ونط

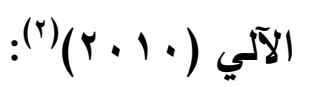

هدفت هذه الدراسـة إلى الكثف عن فعاليـة النظم الخبيرة فى مجـال تتميـة المهارات التعليميـة، وتصميم وبناء نظام خبير كوسيلة ذكيـة لمسـاعدة المتعلم على تتظيم تعلمـه ذاتيا،

(1) أمل خالد محمدين فراج: بناء نظام خبير لإدارة الأزمات في مؤسسات التعليم العالي في مصر , رسالة

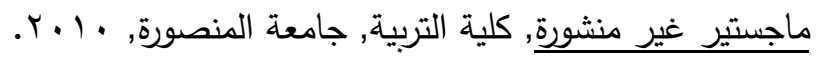

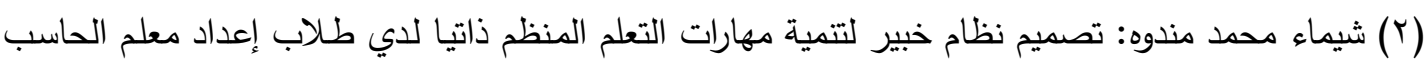

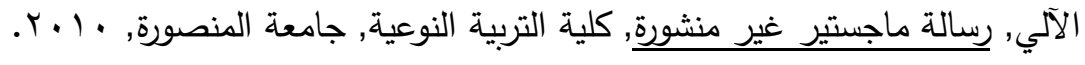




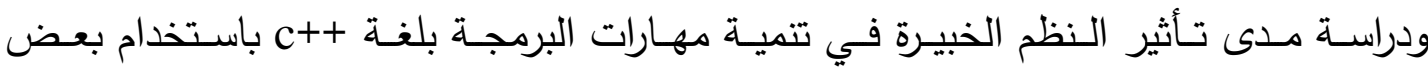
استراتيجيات التعلم المنظم ذاتيا, وبناء اختبار تحصيل وبناء مقياس لبعض استراتيجيات التعلم المنظم ذاتيا، وقد توصلت هذه الدراسة إلى فعالية النظام الخبير في تتمية مهارات التعلم المنظم ذاتيا لاي الطلاب.

لقد تشابهت هذه الدراسة مع البحث الحالى فى تناولها موضوع النظم الخبيرة، إلا أن هذه الدراسة ركزت على تصميم نظام خبير لتتمية مهارات التعلم المنظم ذاتيا لدي طلاب إعداد معلم

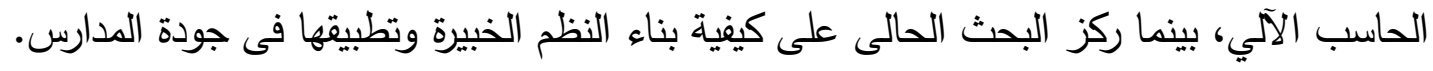

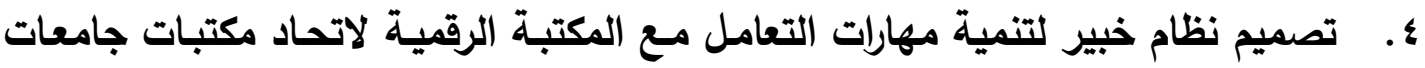

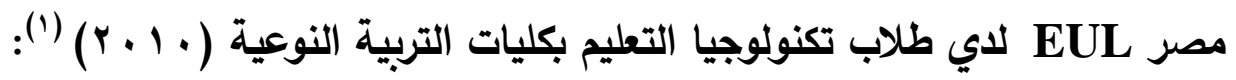

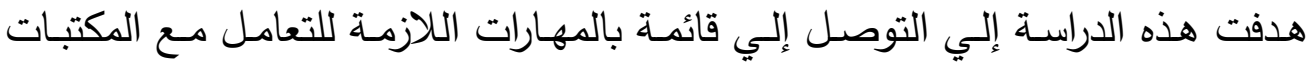
الرقمية لدي طلاب الفرقة الثالثة قسم تكنولوجيا التعليم، وتصميم نظام خبير لتتمية مهارات

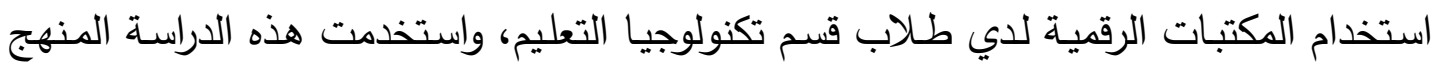

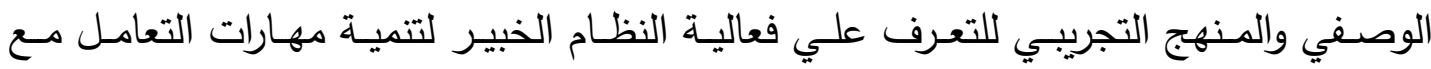

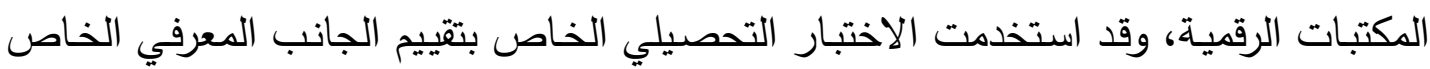
بمهارات التعامل مع المكتبة الرقمية. وقد توصلت هذه الدراسة إلي أهمية استخدام النظم الخبيرة في تتمية المهارات اللازمة

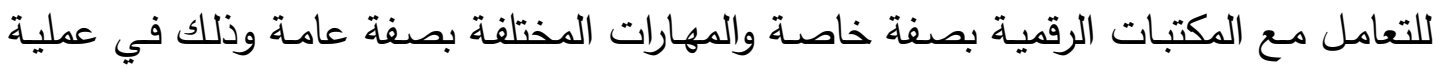

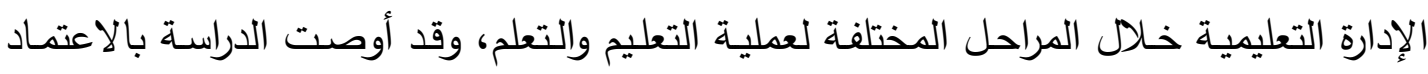

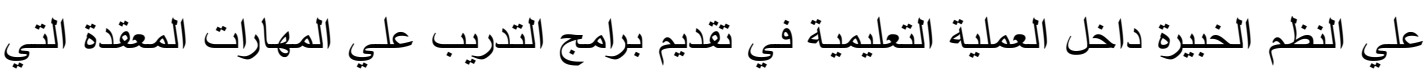
يصعب تعلمها وذلك لاستغلال خصائصها ومميزاتها المختلفة.

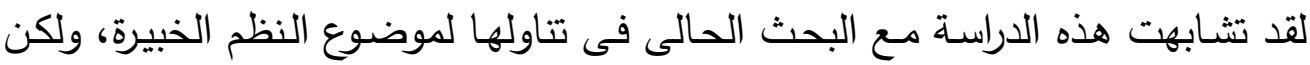

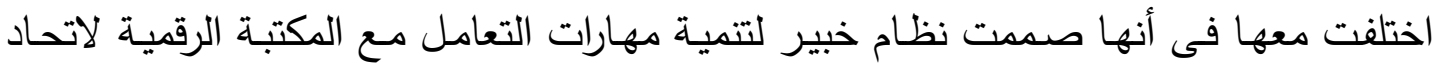

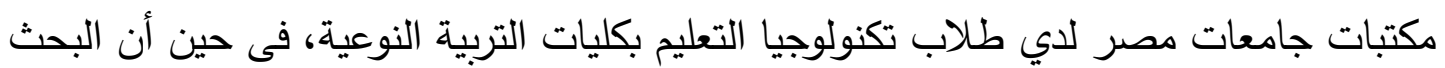
الحالى تناول كيفية بناء النظم الخبيرة وتطبيقها فى جودة الدارس.

( (1) علي عبد الرحمن الصباغ وآخرون: تصميم نظام خبير لتتمية مهارات التعامل مع المكتبة الرقمية لاتحاد

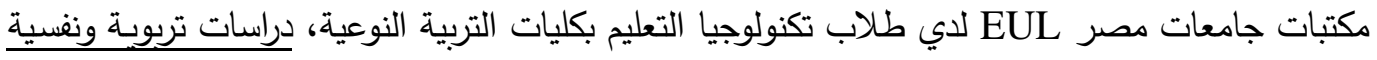

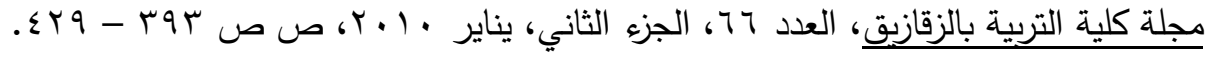


ه. تطبيقات النظام الخبير في بيئة التعليم الاككتروني: تحليل الاتجاهات الحالية والآفق

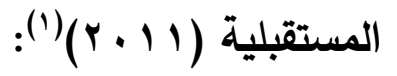

هدفت هذه الدراسـة إلى دراسـة وتحليل تطبيقات النظم الخبيرة في التعليم الالكتروني

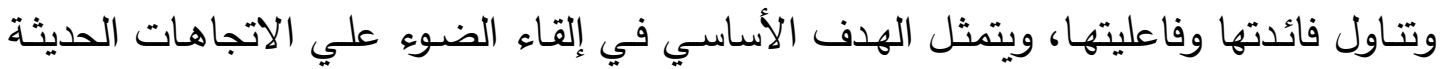

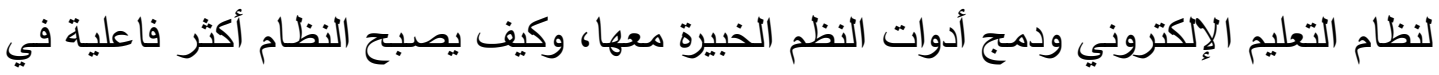

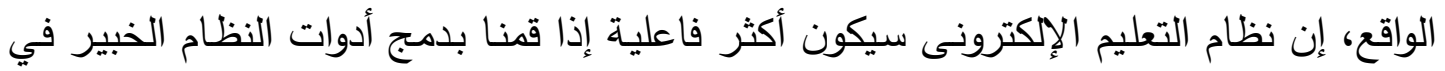

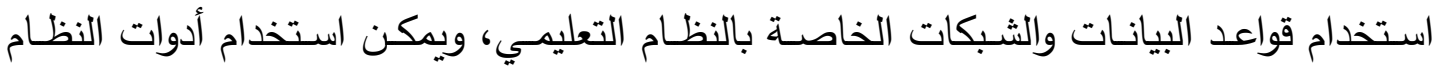

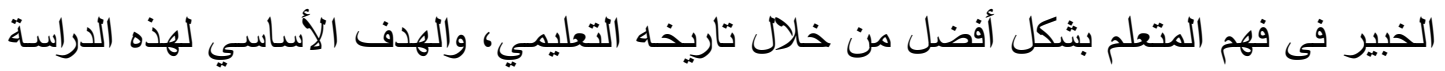

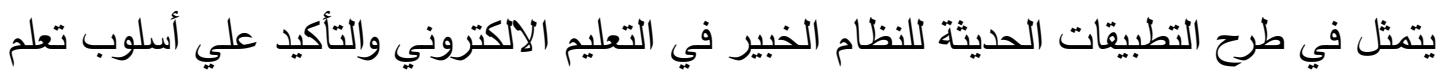

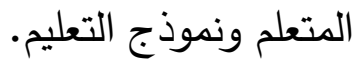

وقد توصلت هذه الدراسة إلى أن أدوات النظام الخبير يمكن استخدامه لفهم الطلاب

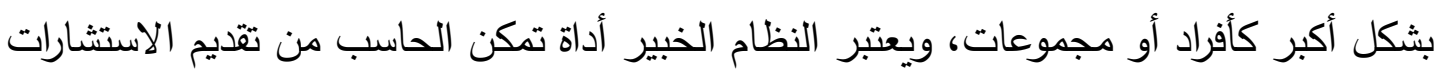

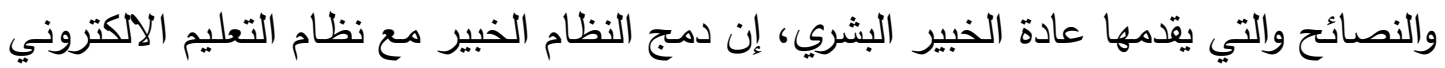
هو الإقتراح الأفضل لتطوير النظام الحالي وجعل النظام أكثر فائدة وفاعلية.

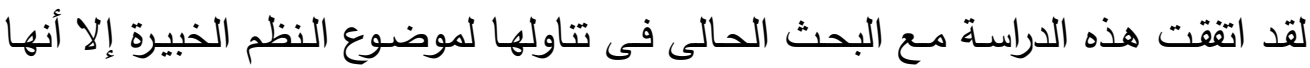
سعت إلى دراسة وتحليل تطبيقات النظم الخبيرة في التعليم الالكتروني وتتاول فائدتها وفاعليتها،

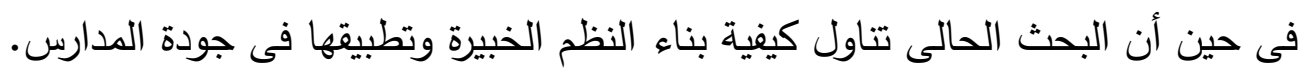
؟. نموذج لنظام خبير قائم على القواعد مزود بقاعدة بيانات شيئية لاختيار التخصصات

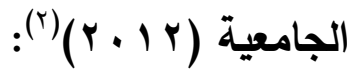

هدفت هذه الدراسة إلى تصميم نظام خبير قائم على القواعد لتوجيه طلاب المدارس الثانوية في اختيار التخصصات المناسبة فى دراساتهم الجامعية، وذلك لتوفير نظام لدعم القرار الذكى لمساعدة الطلاب في اختيار التخصصات الجامعية المناسبة، والتحقق من مدى ملاءمة

(1) Sangeeta kakoty\& Shikhar Kr. Sarma: Expert System Applications in E-learning Environment: Analysis on Current Trends and Future Prospects, International Journal of Internet Computing, Volume I, Issue 1, 2011, Pp.90-93.

(2) Ayman Al Ahmar: A Prototype Rule-based Expert System with an ObjectOriented Database for University Undergraduate Major Selection, International Journal of Applied Information Systems (IJAIS), Volume 4, No.8, December 2012, Pp. 38-42. 


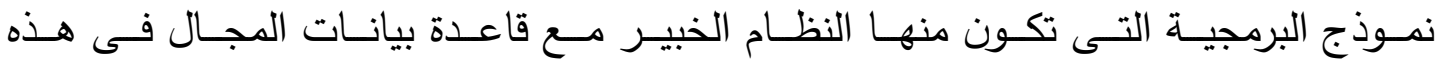
الدراسة، وقدمت هذه الدراسة نموذج لنظام الخبير ووصف لهيكله، ويسمى النظام الخبير المقترح "Major Selection" المجال الهام، وقد توصلت هذه الدراسة إلى أن هيكل النظام الخبير المستخدم أسفر عن برمجية ناجحة لدعم القرار وهي سهلة فى الحفاظ عليها وتعديلها وتوسيعها.

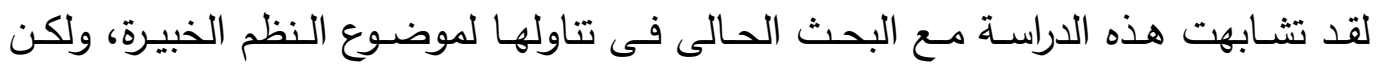

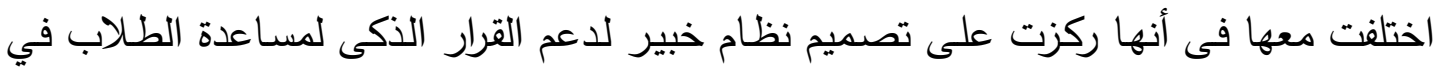

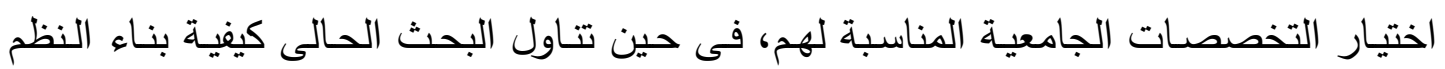
الخبيرة وتطبيقها فى جودة الددارس.

ولقد تناولت كثير من الدراسات والأبحاث المعرفة وإدارتها, إلا أنها لم تتناول كيفيـة استخدامها لحل المشكلات العملية الفعلية، ولذا حاول البحث الحالي تتاول كيفية استخدام بعض الاحل التقنيات مثل النظم الخبيرة- النظم التي توفر استثارة الخبير والتشخيص والتزكيات في ظل التل

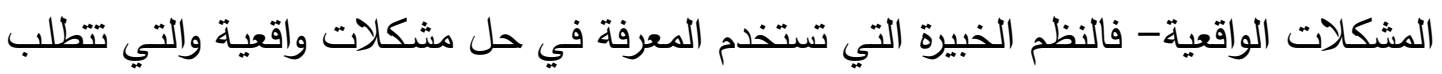

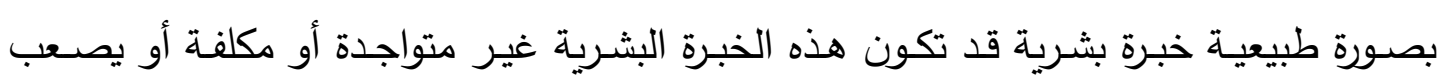
الحصول عليها من الخبراء، أما النظم الخبيرة فيمكن إتاحتها بسهولة عند الطلب.

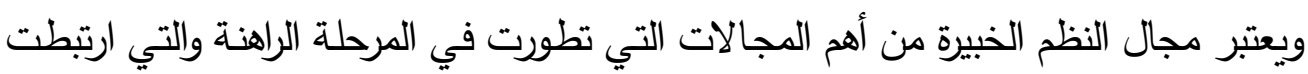

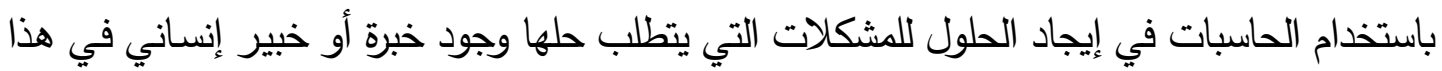

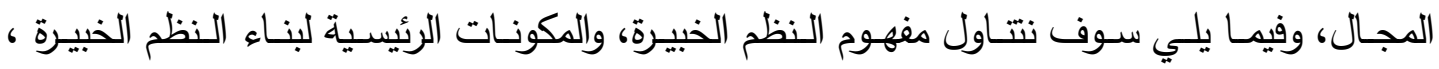
ومميزات ومشكلات النظم الخبيرة، وآلية عمل النظم الخبيرة وتطبيقها في جودة المدارس.

\section{أولاً: مفهوم النظم الخبيرة ( Expert System )} إن الخبير وهو الثخص المتمرس الذي مر بتجارب عديدة صقلت فهمه لمجال من

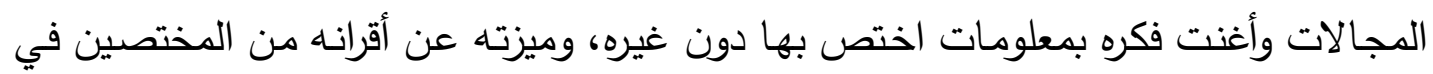

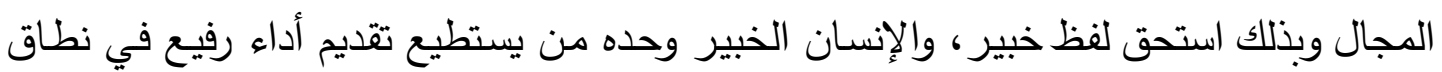
تخصصد، والنظم الخبيرة تستخدم معلومات محصورة في نطاق محدد كي تقدم نفس أداء الخبير

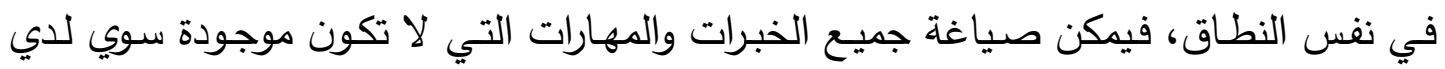
الإنسان الخبير، ويطلق علي النظام الخبير لفظ نظام وليس برنامج لأنه يجب أن أن يشتمل علي 
مكونات لحل المشكلة وأخري مدعمة للعمل وهذه المكونات تشكل محيط الدعم الذي يساعد

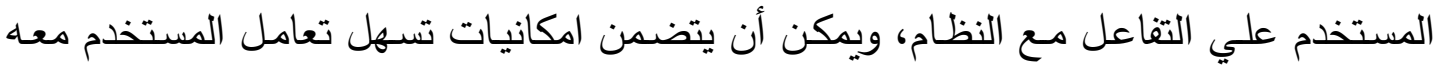

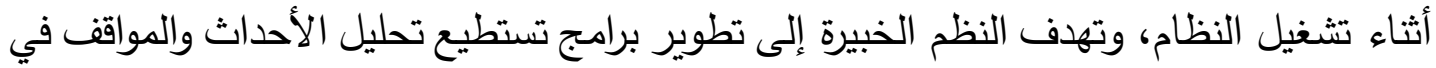

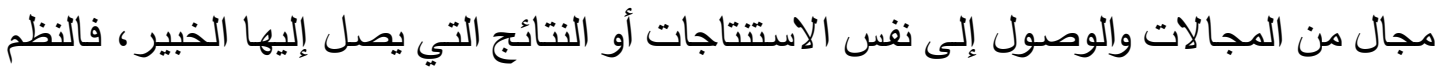
الخبيرة هي برامج تحتوي على الكثير من المعلومات التي يملكها خبير إنساني في حقل معين من لعن لهن

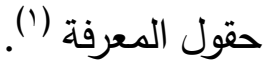

والنظم الخبيرة هى من أهم فروع الذكاء الاصطناعي فهي عبارة عن برنامج حاسب

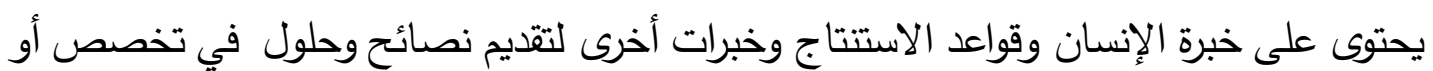
مجال معين، ويمكن للنظم الخبيرة التخزين والمحافظة على الخبرة النادرة التي توجد عند عدد محدود من الخبراء والتي يكون من الصعب استشارتهم في أي لحظة عند اللزوم(؟).

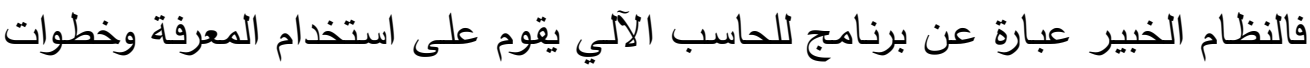
الاستدلال لتتديم حل للمشكلات الصعبة التي تحتاج في حلها إلى استشارة الخبراء، فالنظم الخبيرة

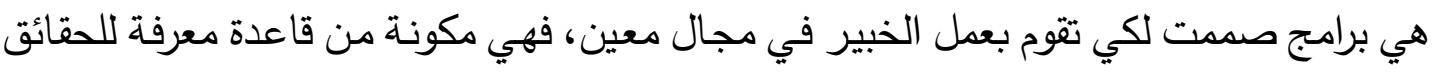
وقواعد البحث التي تضبط كيفية استخدامها ومن المكن استثارتها في أي وقت لمساعدة

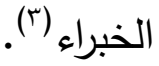

وقد عرف اينر كزاز (Aynur Kazaz) النظام الخبير بأنه هو " برنامج كمبيوتر

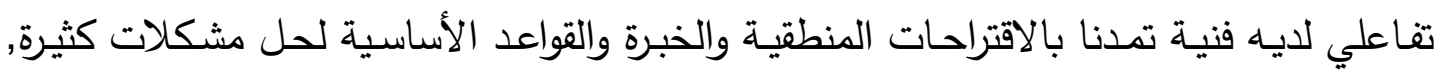

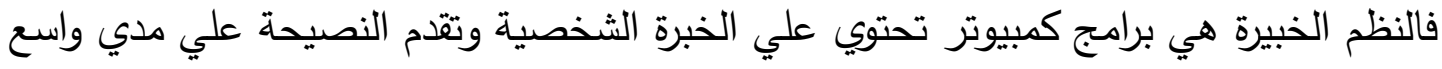

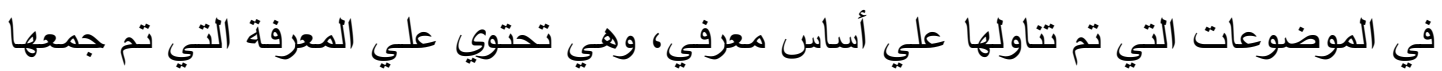

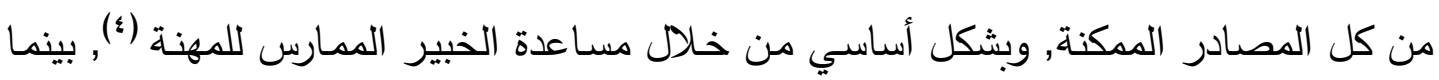

(1) Available on line at: www.abahe.co.uk, P.p25-26, Visited on $r$ th March 2010. (r) عباس برايس: تعليم التحليل والتصميم الإنثائي المقاوم للزلازل باستخدام تقنيات الذكاء الاصطناعي, المؤتمر

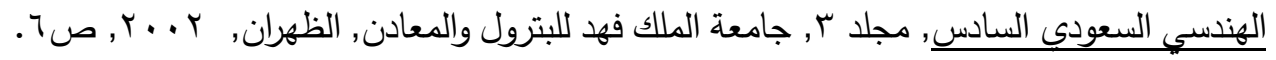

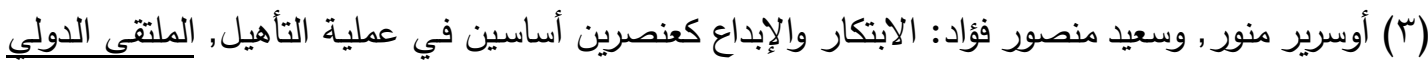

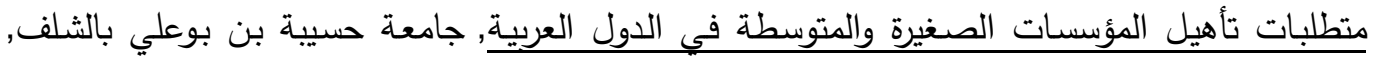

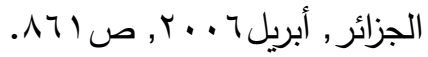

(4) Aynur Kazaz : Application of an Expert System on The Fracture Mechanics of Concrete, Artificial Intelligence Review, Vol 19, 2003, pp.177. 
يرى علي عبد الرحمن الصباغ وآخرون أن النظام الخبير هو نظام كمبيوتري ذكي يقوم بدور

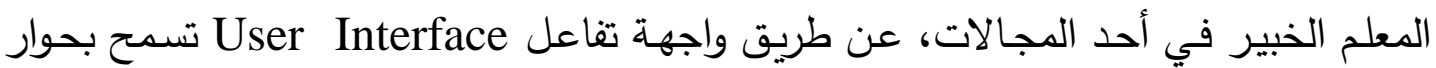
متبادل بين الطالب والنظام عن طريق توجيه الأسئلة والاستفسارات والتدريبات المتنوعة حول

مجال الخبرة مع مراعاة خطوات التعلم الذاتي للمتعلم ليصل بالطالب إلى مرحلة الإتقان (')

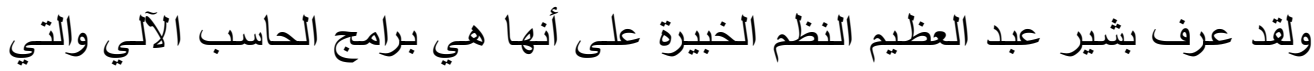

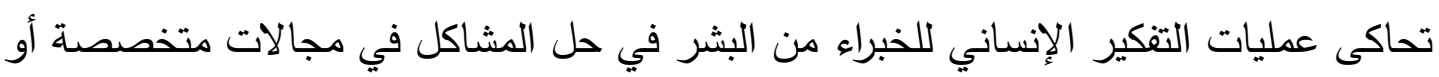

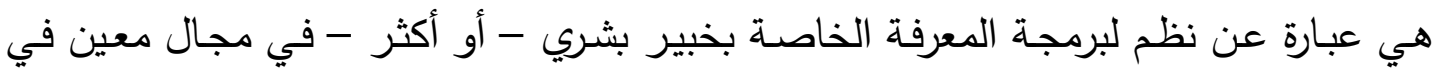

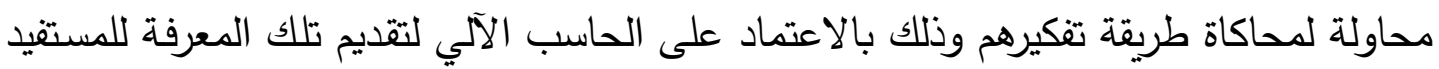
في شكل نصائح أو استثارات مبررة في مواقف معينة (؟). ولقد أشار قاموس ويبستر إلى النظام الخبير على أنه هو نظام قائم على الكمبيوتر

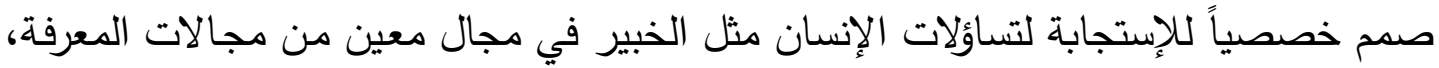
وهذه المعرفة يتم جمعها من الخبراء البشريين ووضعها فى قاعدة المعرفة ولكنها تحتوي على معى القواعد التي يمكن تطبيقها فى حل مشكلة معينة، وواجهة المستخدم تسمح بتحديد وتوضيح

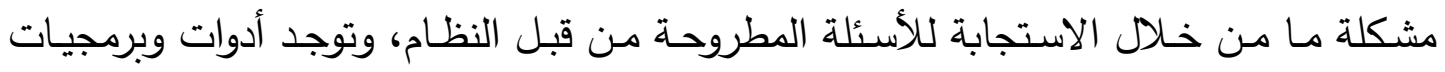

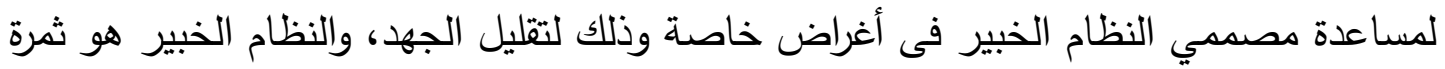

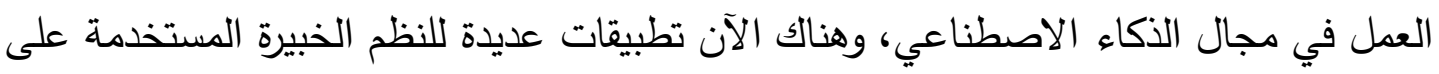
نطاق واسع في مجالات مثل الطب والتعليم (r) . وبناءً على ذلك يمكن تعريف النظام الخبير إجرائياً على أنه هو" برنامج الكمبيوتر الذي يحتوي علي الكثير من المعلومات التي يملكها خبير في حقل معين من حقول المعرفة ويقوم على استخدام قاعدة المعرفة وخطوات الاستدلال وقوانين التنكير والمنطق للوصول إلي حل للمشكلات الصعبة التي تحتاج في حلها إلى استثارة الخبراء".

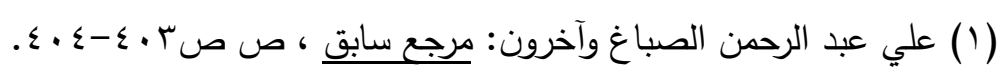

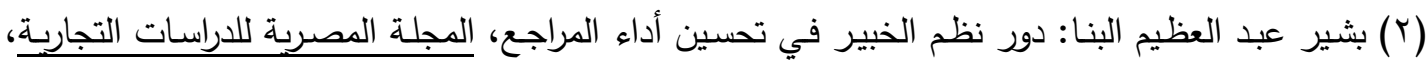

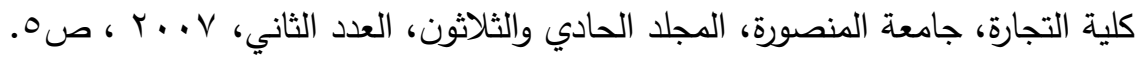
(3) Available Online at http://www.merriamwebster.com/dictionary/expert\%20system Visited on $4^{\text {th }}$ March 2010. 


\section{ثانياً : المكونات الرئيسية للنظه الخبيرة:}

توجد آراء وتقسيمات مختلفة لمكونـات النظسام الخبير ولكن سوف نعرض أهم هذه

الدكونات ويوضح الثكل التالى مكونات النظام الخبير:

شكل رقم (1) يوضح مكونات النظام الخبير

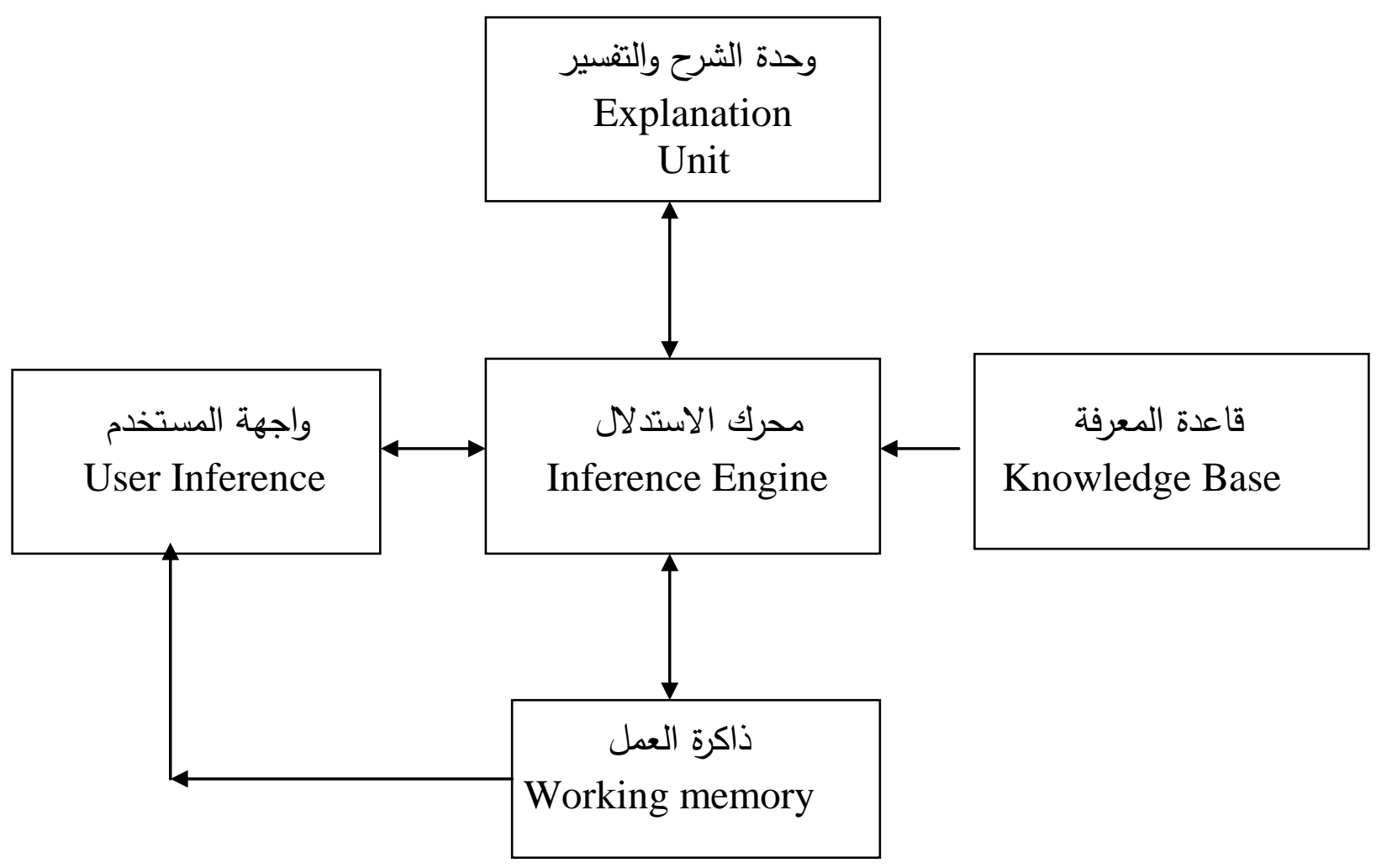

Source: John Durkin, P.28 $8^{(1)}$.

وسوف نتناول كل عنصر من مكونات النظام الخبير بالثرح فيما يلى:

ا- قاعدة المعرفة (Knowledge Base)

قاعدة المعرفة هى جزء من النظام الخبير الذي يحتوي علي المعرفة المجالية، ووظيفة

مهندس المعرفة تتمثل في الحصول علي المعرفة من خبير المجال وتثفيرها في قاعدة المعرفة

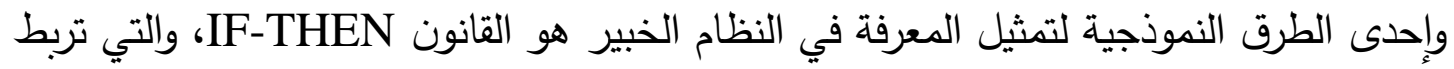

(1) John Durkin : Expert Systems Design and Development, MacMillan Publishing Company, A Division of MacMillan Inc, USA, 2009, P.28 . 


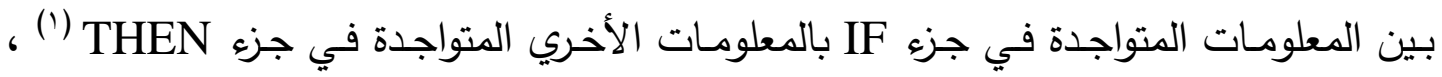
وقاعدة المعرفة هي قلب أي نظام خبير وتضم الحقائق المحددة حول مجال الخبرة المطلوبة.,

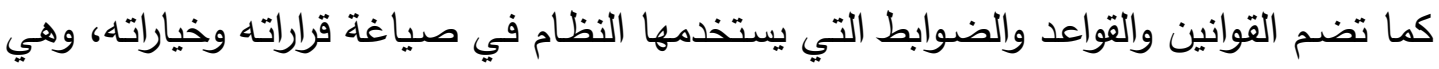

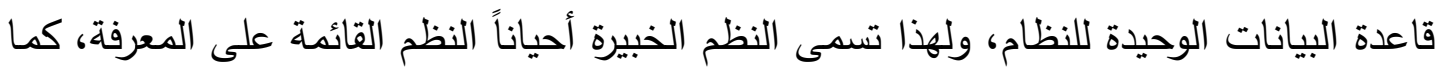

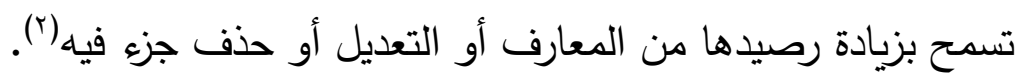

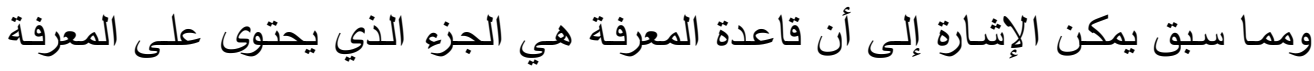
والخبرة الدكتسبة من التجارب العملية اللازمة لحل المشاكل في المجال الذى نريد إنشاء النظام الخبير من أجله.

\section{r- محرك الاستدلال ( Inference Engine ):}

محرك الاستدلال هو العقل المفكر ( Brain ) للنظام الخبير وهو في الواقع برنامج للحاسب يقوم بالتخطيط لمنهجيات ( Methodologies ) وأساليب الاستتتاج المنطقي للمعلومات الموجودة في قاعدة المعرفة وساحة العمل ( Work Space ) للوصول إلى الاستتناجات المطلوبة التي تساهم في حل المشكلة واستتباط المسبيات التي تؤدى إلى هذا الحلى (†).

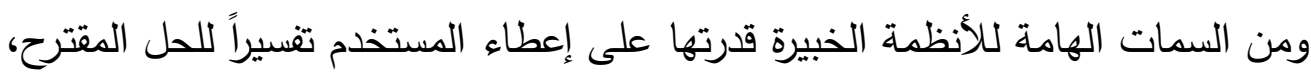

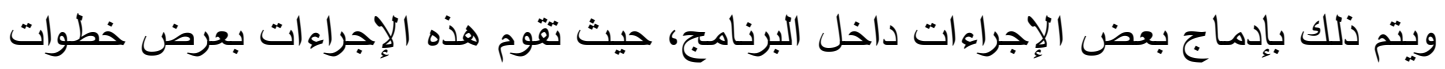

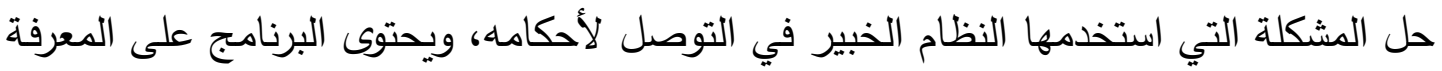
أو المعلومات في صورة لا تختلف كثيراً عن صورة المعرفة كما يدركها الخبير البشري.

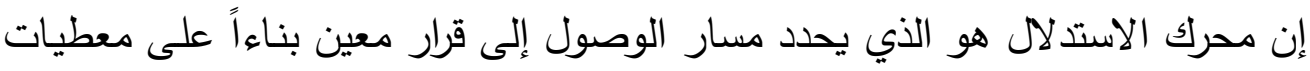

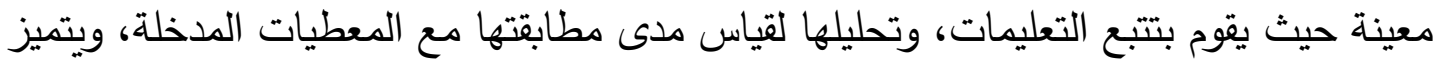

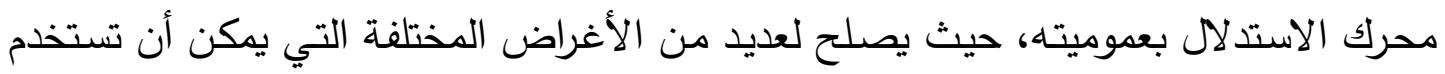

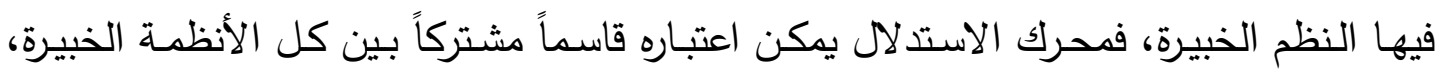

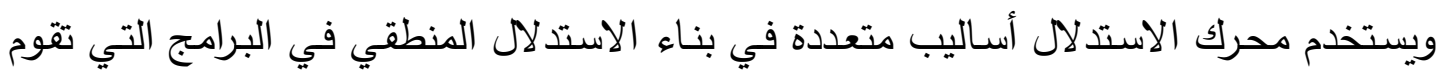

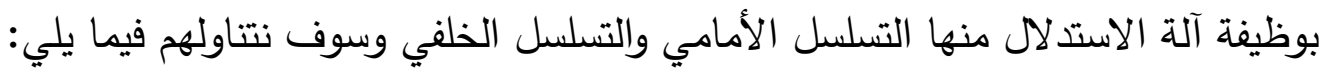

(1) Ibid, P.28 .

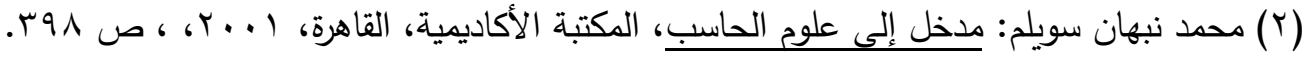

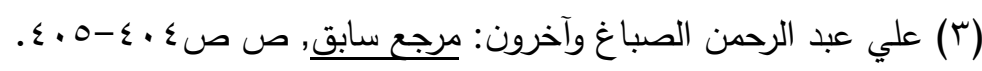


التسلسل الأمامي Forward Chaining : يكون التسلسل للأمام تفكيراً تديره البيانات data driven ، يبدأ التفكير من بيانات معروفة، ويستمر إلى الأمام مع هذه البيانات، وفي لإني

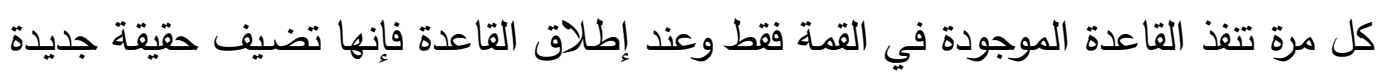

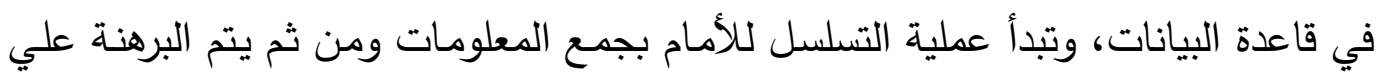
هذه المعلومات لاستخلاص الاستنتاجات المنطقية، ويتم تطبيق التسلسل للأمام في النظام

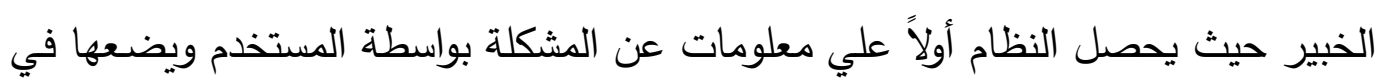

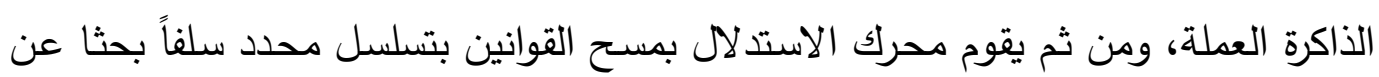

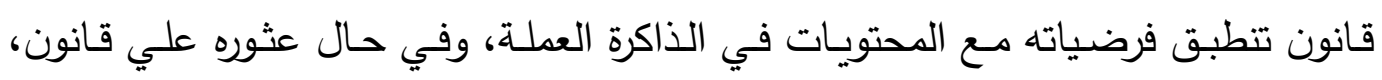

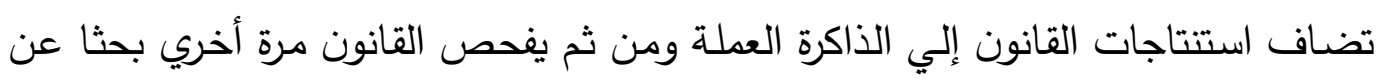

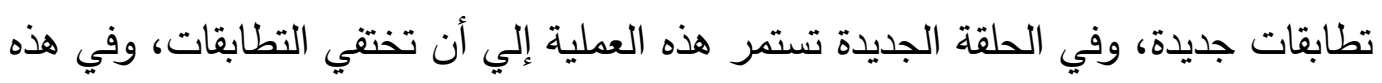

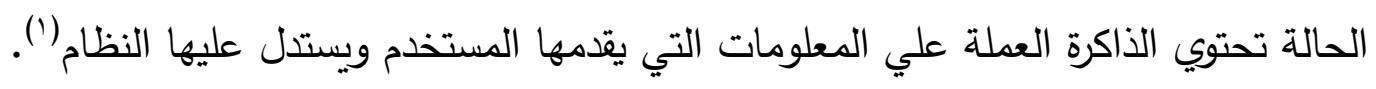
التسلسل للخلف Backward Chaining: يكون التسلسل للخلف تقكيراً يديره الهدف goal - driven

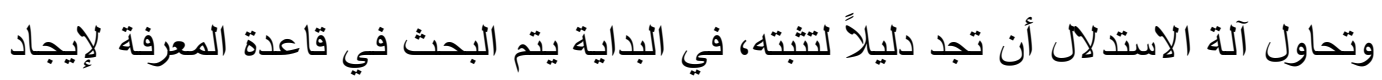

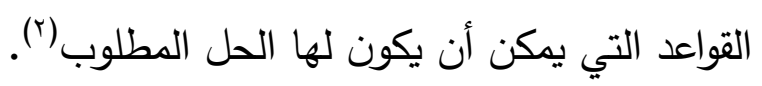

ويمتاز التسلسل للخلف بأنه يقرب محرك الاستـلال من الأهداف التي يرغب في

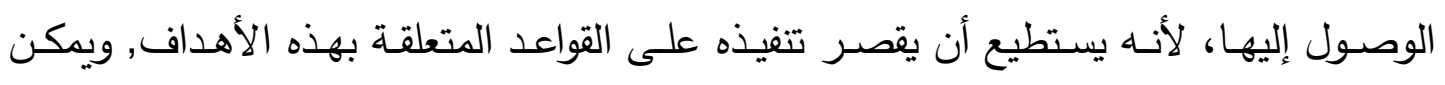

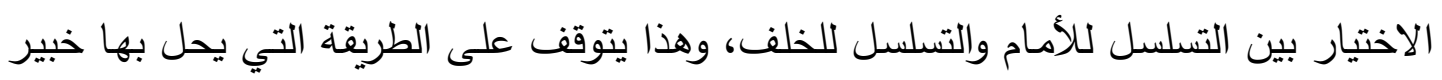

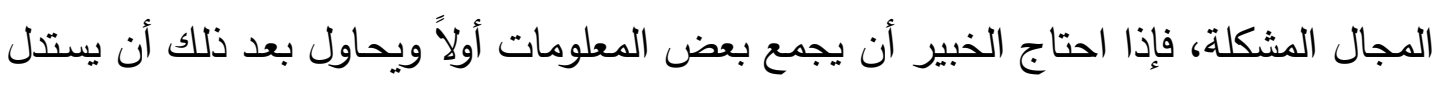

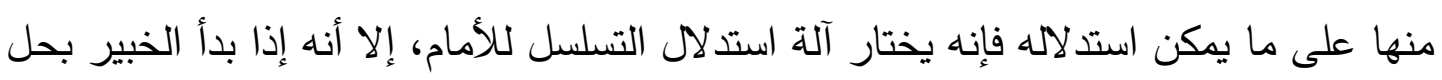

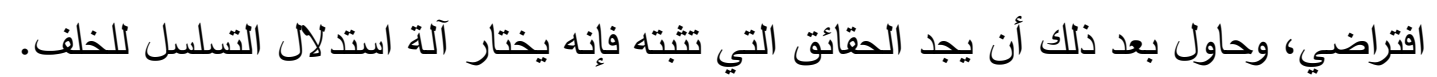

(1) Comparison of Chaining Methods (5) . available on line at http://www.expertise2go.com/website/tutorials/ESIntro/ Visited on $\varepsilon$ th March 2010 .

(2) Comparison of Chaining Methods (5). Available on line at http://www.expertise2go.com/website/tutorials/ESIntro/ Visited on $\varepsilon$ th March 2010. 


\section{r- ذاكرة العمل (Working Memory):}

هى جزء من النظام الخبير الذي يحتوي علي حقائق المشكلة التي تم اكتشافها خلال التشـاور مـع النظام الخبير، ويقوم المستخدم بإدخال المعلومـات عن مشكلة محددة في ذاكرة العمل، ويربط النظام بين هذه المعلومات والمعرفة الموجدة في قاعدة المعرفة للاستدلال عن حقائق جديدة، ومن ثم يقوم النظام بإدخال هذه الحقائق الجديدة في ذاكرة العمل وتستمر عملية المطابقة، وتحتوي ذاكرة العمل علي كافة المعلومات الخاصة بالمشكلة التي يقدمها المستخدم أو التي يستدل عليها النظام، وتستطيع العديد من تطبيقات النظام الخبير الاستفادة من المعلومات المتواجدة في الذاكرة مثل قواعد البيانـات والجداول، ويستطيع النظــام أن يقوم بتحميـل هذه المعلومات في الذاكرة العاملة في بداية الجلسة أو الوصول إليها خلال جلسـات التشـاور كلما كان هنالك حاجة إلي ذلك(').

\section{گ- واجهة المستخلدم (User Interface):}

هي الوسيلة التي تصل المستخدم بالنظام الخبير ، ويحدث التفاعل بين النظام الخبير والمستفيد من خلال أسلوب تفاعل يتميز بالبساطة والقرب الثديد من أسلوب الحوار الشخصي وتصمم الواجهات على أسـاس تلبية احتياجات ومتطلبات المستخدم، وتسمح لله بالتفاعل بيسر وسهولة (r), ويستطيع المستخدم من خلال واجهة المستخدم إدخال المعلومات والتعليمات إلى لي النظام وتوجيـه الأسئلة وتلقى الإجابات، وغالباً مـا تهدف تكنولوجيا النظم الخبيرة إلى تزويد واجهة المستخدم باللغات التي تمكن المستخدم من التفاعل بسهولة مع النظام (ّ). ولهذا فإن التفاعل بين النظام الخبير والمستخدم يتم إجراءه بأحد اللغـات الطبيعيـة، ويشبه التفاعل أيضـا بدرجة كبيرة المحادثة التي نجدها بين البشر، ولإجراء هذه العملية علي نحـو مقبـول للمسـتخدم، نضـع مطالب خاصــة عنـــ تصـميم واجهـة تفاعـل المسـخـدم، ومـن المتطلبات الأساسية لتصميم واجهة تفاعل المستخدم هو طرح الأسئلة للحصول علي معلومات حقيقية من المستخدم، وتحتاج أيضاً إلي الاهتمام بتصميم السؤال، وهذا قد يتطلب منا تصميم

(1) John Durkin: Op.cit, P.29 .

$$
\text { (2) نهير طه حسن: مرجع سابق، ص سب (2) }
$$

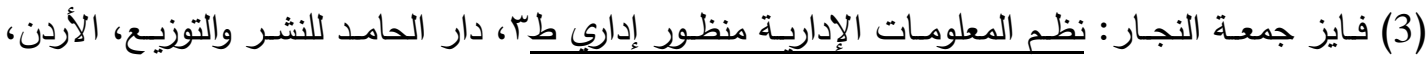


واجهة تفاعل المستخدم باستخدام القوائم والرسوم البيانية أو الثاشات، وقد يطلب من المستخدم

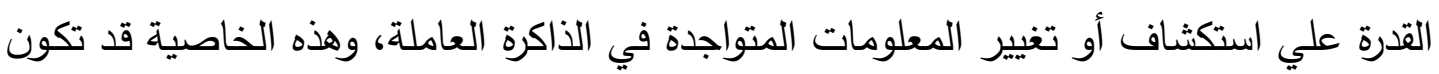

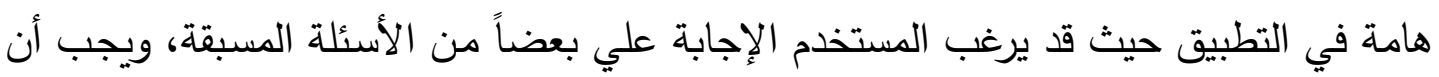
تكون علي وعي بمنطلبات المستخدم وتصميم واجهة تفاعل المستخدم للإِيفاء بها.

\section{0- وحلدة الشرحوالتفسير تxplanation Facility Unit}

تقوم وحدة الثرح والتفسير بالتوضيح للمستخدم معرفة كيف أتم النظام الخبير دراسـة

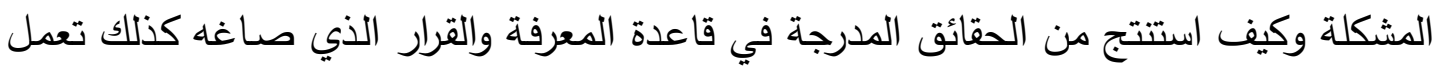
هذه البـرامج على لفت نظر المستخدم إلى حتميـة إدخـال بعض بيانـات تتطلبهـا عمليـة

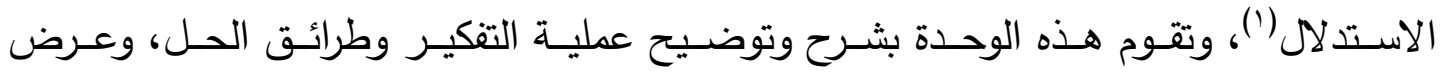

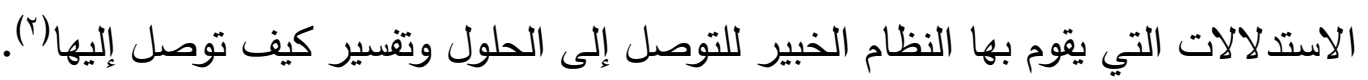

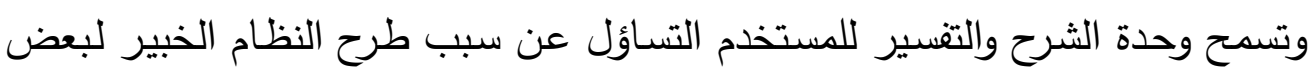

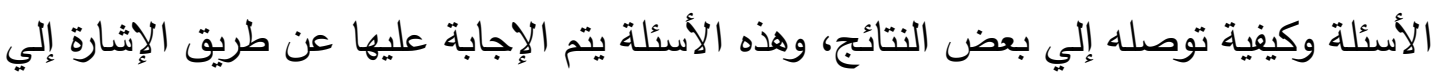

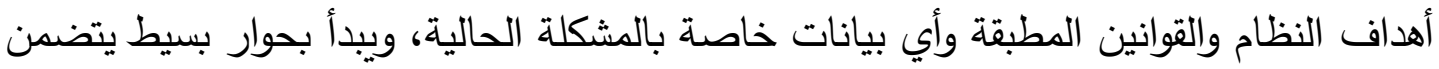

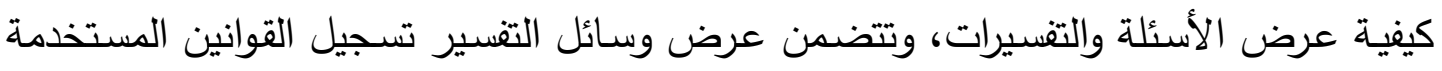

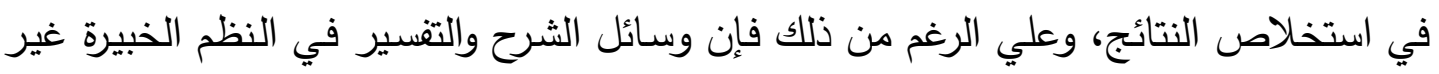

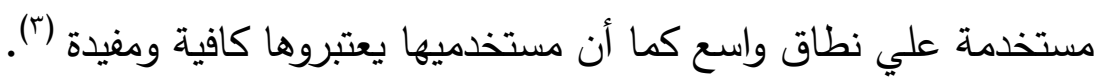

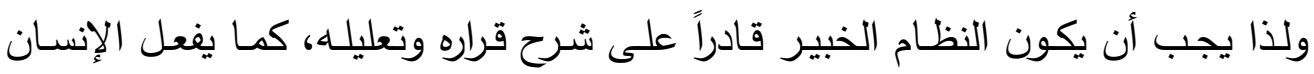
الخبير، وذلك بهدف تعزيز ثقة المستخدم بالنظام، فعلى سبيل المثال إذا كان مدير المدرسة

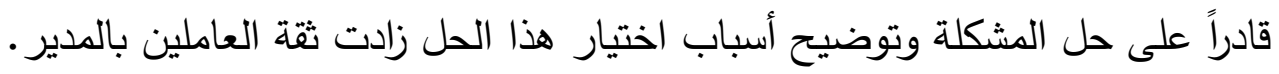

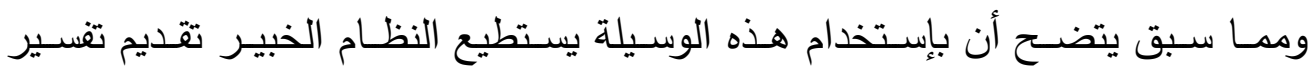

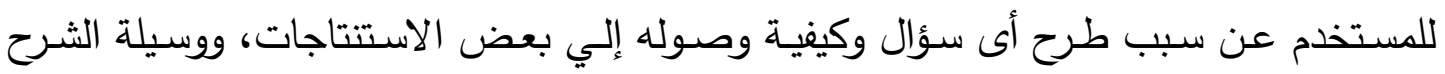

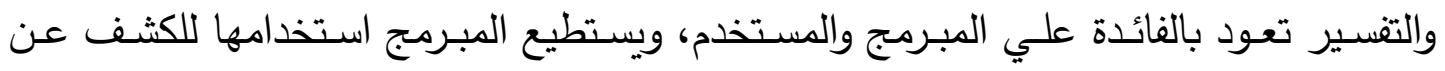
الأخطاء في معرفة النظام، ويستقيد المستخدم من الثفافية المتواجدة في النظام، وبالإضافة إلى الئي تقديم نتيجة نهائية.

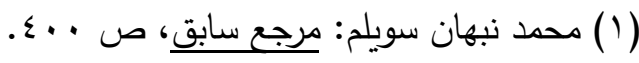

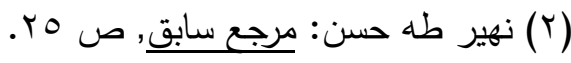

(3) Alison Cawsey: The Essence of Artificial Intelligence, Prentice Hall Europe, England, 2008, P.49. 
ويشترك فى بناء وتكوين النظام الخبير مجموعة من المتخصصين والخبراء :

إن المشاركين الأساسيين في بناء وتكوين النظام الخبير هم مهندس المعرفة وخبير

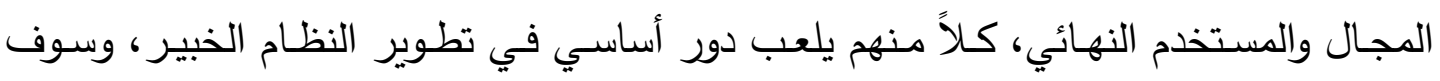
نستتعرض الدور المنوط به كل فرد منهم فيما يلى:

\section{1- خبير المجال (Domain Expert)}

خبير المجال هو شخص واسع المعرفة وذو سمعة بارزة وواضحة في إعطاء حلول

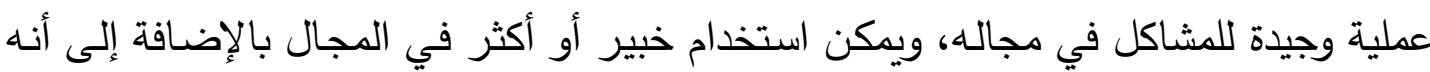

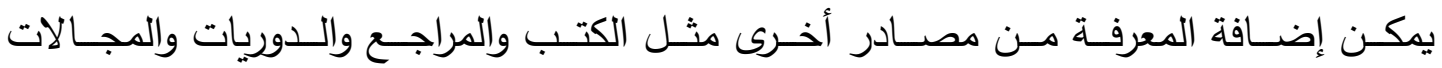

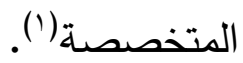

إن الاختلاف الجوهري بين الخبير والغير خبير يتمثل في المعرفة التي يمتلكها الخبير

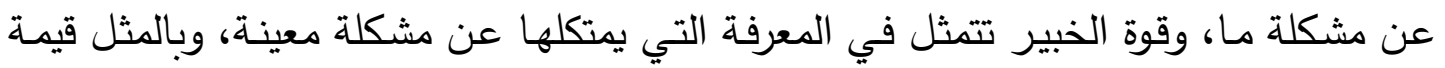

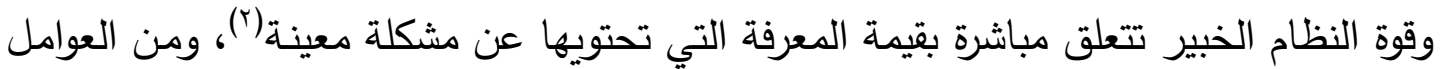

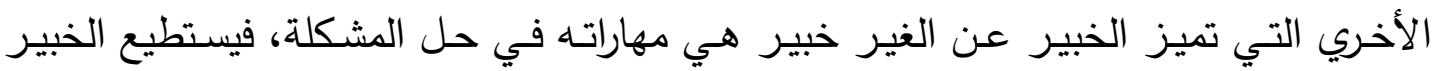
الإدلاء عادة بالمعلومات الهامة التى يستخدمها للوصول إلي حل فعال، فاليز فالخبير يمتلك المعرفة

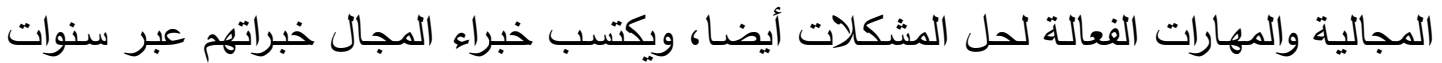

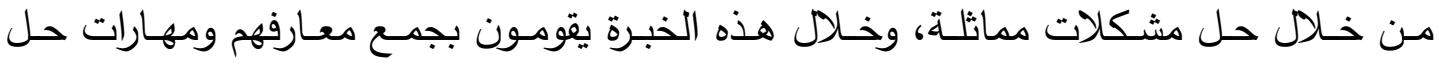
المشكلات في صيغة مدمجة تمكنهم من حل المشكلات بفاعلية (r). وخبير المجال هو شخص ذو أهمية كبري في تصميم النظام الخبير ، فيجب أن أن يكون

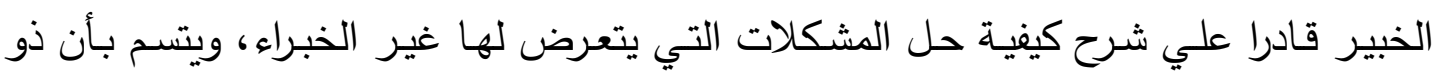
معرفة واسعة وقد اكتسب الخبرة من خلال ممارسته العملية خلال سنوات طويلة، وقد تدرب وقام بحل مشكلات عديدة فى مجال تخصصه.

( (1) جمال عبد المعطي، مصطفى رضا عبد الوهاب: الحاسب والذكاء الاصطناعي ، سلسلة دلتا لتبسيط

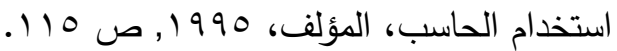

(2) Joseph L. Heller Stein et al: Expert Systems in Data Processing: Applications Using IBM's knowledge Tool, Addison Wesley Publishing Company INC, New York, 2012, P.p. 10.

(3) M. Murtaza, J. Shah, \&V. Gupta: Artificial Intelligence Applications in Ecommerce: Current trends and Future prospects" Proceedings of the Academy of Information and Management Sciences, Nashville. Vol. 6, No. 1, 2010,, P. 17. 


\section{- Knowledge Engineer مهندس المعرفة -}

مهندس المعرفة هو شخص لايـه خلفيـة ودراية بعلم الحاسبات والذكاء الاصطناعي،

ويعرف جيداً كيف يتم بنـاء النظم الخبيرة، ويقوم مهندس المعرفة باستجواب الخبير تفصيلاً واستخلاص حصيلة المعـارف المتراكمـة لديـه وتتظيمها وتحديد الأسلوب الأمثل لتمثيلها في النظـام الخبير (')، وتوجد بعض المهارات التي يجب أن يتسم بها مهندس المعرفـة في بنـاء النظـام الخبير هـ أن يتمتع بمهارات هندسـة المعرفة، وأن يتمتع بمهارات تواصل جيدة، وأن يستطيع الربط بين المشكلة والبرمجية، وأن يتمتع بمهارات برمجة النظام. وهندسة المعرفة هي فن بناء النظام الخبير، فمهندس المعرفة يجب أن يحدد أولاً جدواها لحل المشكلة بإستخدام النظام الخبير، وتقييم الجدوي يتضمن دراسـة خصائص المشكلة لتحديد مدي احتمالية حل النظام الخبير (؟)، ويقوم مهندس المعرفة باستخلاص الاستراتيجيات والأساليب والقواعد التي يمارسها الخبير في حل المشاكل المتعلقة بمجال خبرته والتي اكتسبها من تدرببه وممارسته العمليـة وتجاربـه لسنوات طويلـة في هذا المجـال، ثم يقوم مهندس المعرفـة بوضـع حصيلة مـا تم استخلاصـه من الخبير والذي يمثل المعرفة في هذا المجال في النظام الخبير الذي يقوم ببنائه، ولذلك فإن هندسة المعرفة تعتمد أساساً على دراسـة الخبرة البشرية من أجل تصميم برامج تتسم بالذكاء والكفاءة(). ومما سبق يمكن أن نستخلص أن مهندس المعرفة هو الثخص الذي يقوم بتصميم وبناء واختبار النظام الخبير، وهو المسئول عن اكتساب ومعالجة وترميز المعرفة، ومهندس المعرفة مماثل للمبرمج التقليدي حيث يقوم كلاً منهما بصياغة شفرة الحاسب، وعلي الرغم من ذلك فإن مهندس المعرفة مسئول أيضاً عن المهام الغير مماثلة لمهام المبرمج التقليدي، ولإنجاز هذه المهام يجب أن يكون المهندس مـاهر في مجال هندسـة المعرفة، ويقوم مهندس المعرفـة بتطوير البرامج المختلفة التي تمثل أحد مكونات النظام الخبير •

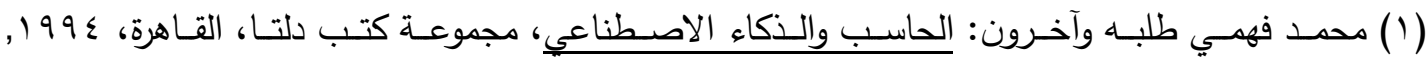

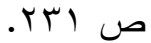

(r) M. Murtaza, J. Shah, \&V. Gupta: Op.cit, P. 19.

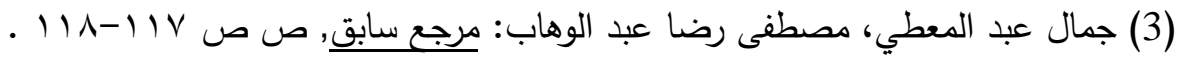




\section{1- المستخلد النهائي (End User):}

وهو المستفيد النهائي مـن النظـام وهو الثــص الذي بحاجـة للنظـام، ففي العمليـة

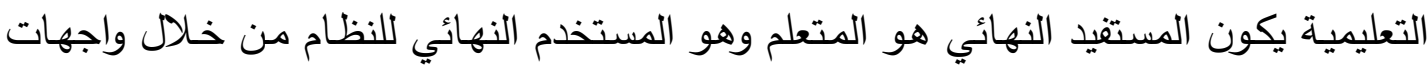
النظام والتي تصمم بلغات البرمجة بحيث تكون واضحة ومرنة وسهلة الاستخدام, والمستخدم هو

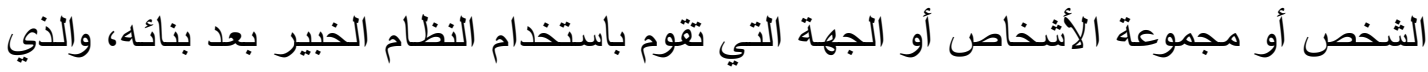
تم عمله أساساً من أجلهم، وطبقاً لطبيعة المجال الخاص الجهة بالنظام الخبير ('). والمستخدم النهائي هو الثخص الذي سيعمل أخيراً مع النظام، وسيعتمد القبول النهائي للنظام بدرجة كبيرة علي مدي تحقيق النظام لاحتياجات المستخدم النهائي، تاريخ النظم الخبيرة مليئة بالنظم التي لاقت نجاح تقني، ويتم ادخال المعلومات في النظام الخبير بواسطة وسائل

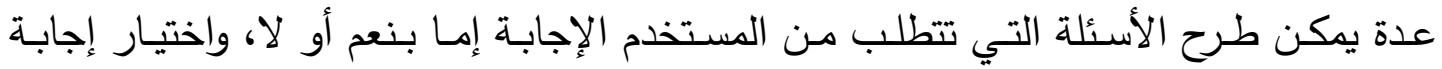

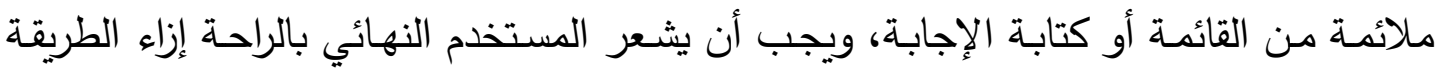
التي يعطي بها النظام الإجابة، وقد يطلب المستخدم النهائي من النظام تقديم تفسيرات لـنس لمنطقها

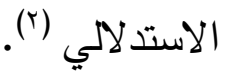

ومما سبق نستخلص أنه لكى نقوم ببناء أو تطوير إحدى النظم الخبيرة فلا بد أن نكون على دراية ووعى تام بما هية الككونات الرئيسية للنظم الخبيرة، وما الغرض الذى سوف يستخدم فيه هذا النظام، وما الطريقة المثلى التى نتبعها لبناء النظام الخبير، وأى الأشخاص يمكن أن الن النائ

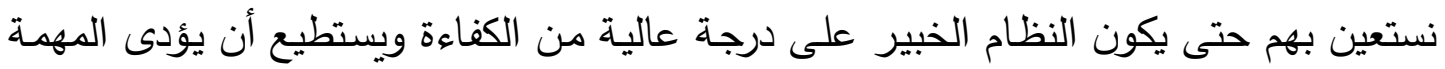
التى وضع من أجلها.

\section{ثالثاً: مسيزات ومشكلات النظم الخبيرة:}

تعتبر تقنية النظم الخبيرة طريقة فعالة للحصول علي الخبرة البشرية وإدماجها فى نظم

الحاسب الآلىى، فـن جهه قد يؤدي الإستخدام الغير ملائم للنظم الخبيرة إلي زيـادة الوقت المبذول في بناء النظم الخبيرة، ومن جهة أخرى قد يكون النظام الخبير أكثر فاعلية وكفاءة في

( ) آلان بونيه: الذكاء الاصطناعي واقعه ومستقبله، ترجمة علي صبري فرغلي، عالم المعرفة، الكويت،

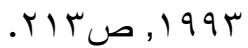

(1) M. Murtaza, J. Shah, \&V. Gupta: Op. cit, P. 21. 
حال استخدامه للتقنيات الملائمة للوظائف الملائمة لها، ونستعرض فيما يلى مميزات ومشكلات النظم الخبيرة: - (20)

1. مميزات النظم الخبيرة: للنظم الخبيرة مجموعة من المميزات يمكن ايجازها فيما يلى:

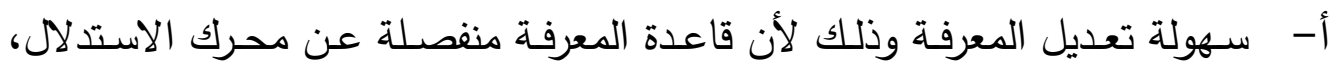
ولهذا يكون من السهل التعديل فى قاعدة المعرفة بالإضافة أو الحذف ألى أو التعديل وذلك لا يتطلب إعادة برمجة النظام.

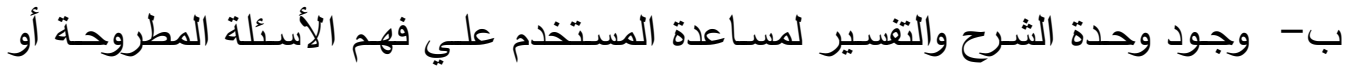

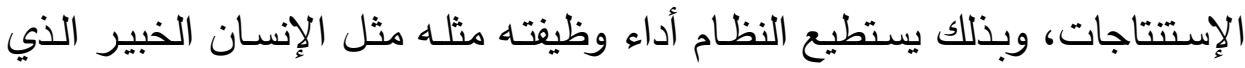
يفسر العمليات الإستتناجية المتضمنة فى إقتراحاته. ج- النظم الخبيرة مفيدة فى النطبيقات الثابتة ذات القوانين المحددة بوضوح و ويمكن صياغة النظم الخبيرة بسهولة للوصول إلي أداء جيدات

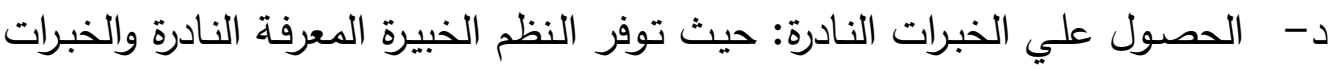
المميزة في مجال معين وتسمح للآخرين باستخدامها بسهولة، فمن الممكن أن يكون

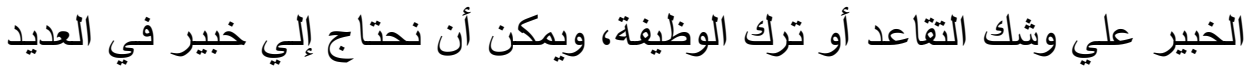

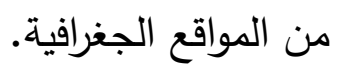

هـ - المرونة: تتسم النظم الخبيرة بالمرونة في الحلول المقدمة للمستخدمين، فبناء علي نوع المدخلات تتخذ القواعد في حل المشكلات.

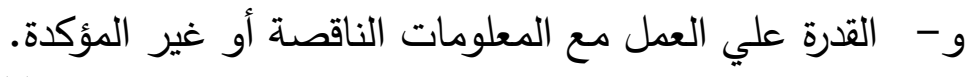

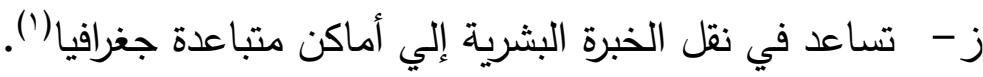
ح- تققليل الوقت وتخفيض تكلفة القرارات على مستوى الخبراء من قبل غير الخبل الخبراء. ط- تعزيز الإستفادة من معظم البيانات المتاحة.

ي - تحرر عقل ووقت الخبير البشرى لتمكنه من التركيز على الأنشطة الأكثر إبداعاً. ك- - يوفر النظام الخبير بيئة مناسبة للإستعلام والإستفسار ومعرفة الحلول للمشكلات.

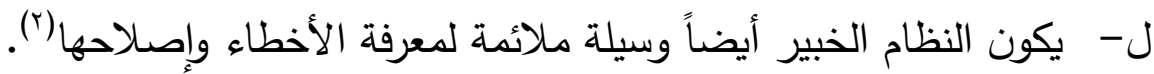

(1) David L. Poole \& Alan k . Mackworth: Artificial Intelligence Foundation of Computational Agents , Combridge university press , England , 2010 , p.6.

(2) Nwigbo Stella N, and Agbo Okechuku Chuks: Expert System: A Catalyst in Educational Development in Nigeria, Proceedings of the 1 st International Technology, Education and Environment Conference, African Society for Scientific Research (ASSR), 2013, Pp.566-567. 
ونستخلص مما سبق أن أهم ما يميز النظم الخبيرة هى أن النظم الخبيرة تستخدم فى في

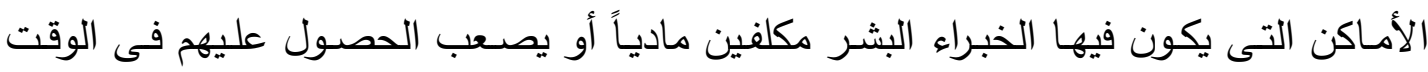

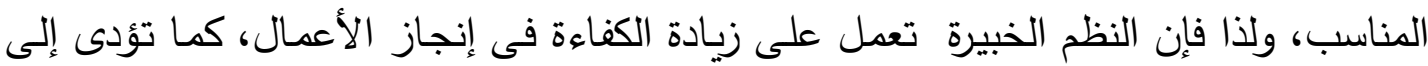
توفير النفقات وزيادة مرونة العمل وتحقيق درجة رضا أكبر لكستخدميه.

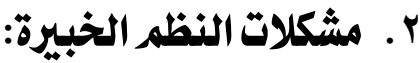

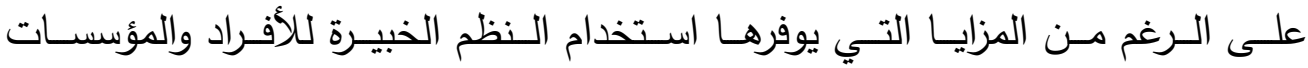

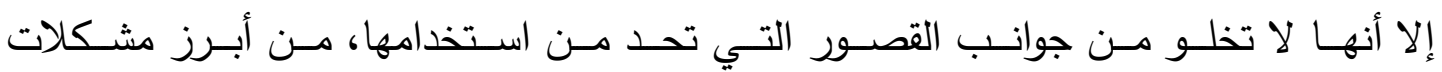

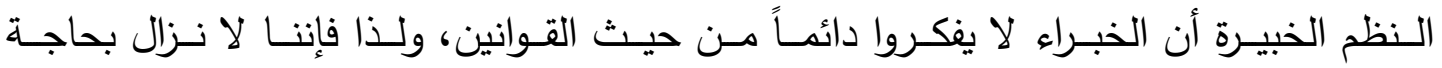

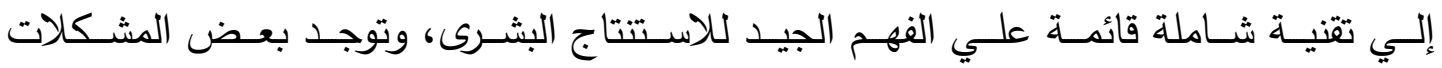
التي قللت من انتشار النظم الخبيرة وهى ما يلى ('): أ- إن المشكلة الأساسية في النظم الخبيرة هى اكتساب المعرفة، إلا أن النظم الخبيرة لا تزال تتطلب جهود مكثفة لاستنباط المعرفة من الخبير البشري. ب- - أن المعرفة ليست متاحة علي الدوام. ج- من الصعب الحصول على الخبرات من الإنسان. د- يختلف اتجاه كل خبير لتقييم الموقف علي الرغم من صحته. هـ - تتجح النظم الخبيرة في الحقول المحدودة فقط. و - اللغة الاصطلاحية التي يستخدها الخبير للتعبير عن الحقائق والعلاقات محدودة عادة ولا

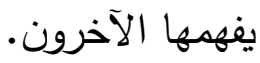
ز - نحتاح إلي مساعدة مستمرة من مهندسي المعرفة الغير متوفرين علي الدوام ومكلفين للغاية، الحقيقة التي تجعل من بناء النظم الخبيرة أمراً باهظاً للغاية.

ح- الإفتقار إلي الثقة من جانب المستخدمين النهائيين يعد عائق أمام استخدام النظم الخبيرة. وبالرغم من الفوائد العديدة للنظم الخبيرة إلا أن مناهج النظم الخبيرة المتوفرة ليست دائماً

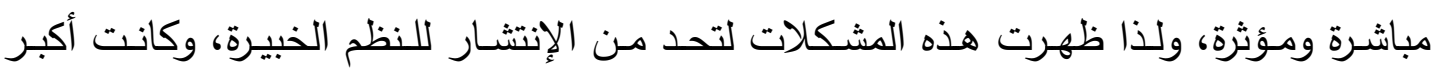

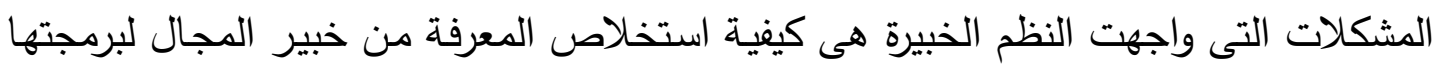

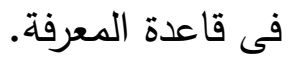

(1) Alison Cawsey : Op. cit, P.49 . 


\section{رابها:ً: آلية عمل النظم الخبيرة وتطبقهما فى جودة المدارس:}

تصمم النظم الخبيرة بطرق مختلفة وذلك حسب الهدف الذي يوضع من أجلها، والذي

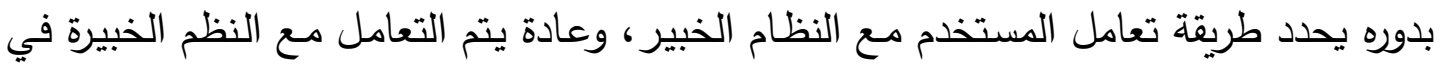

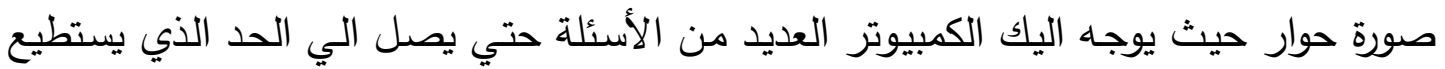

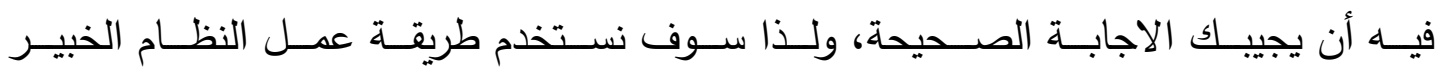
(وهو من أوائل الأنظمة الخبيرة في الطب وأثشهرها ) حيث يبدأ النظام (مايسين) Mycin عادة بأسئلة عامة عن الاسم والسن والوظيفة, وسوف نتناول آلية عمله فيما يلى:

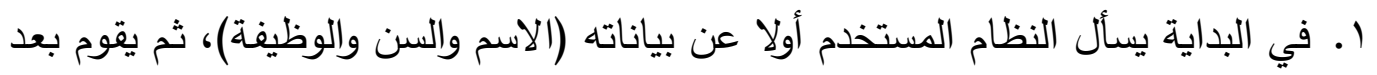

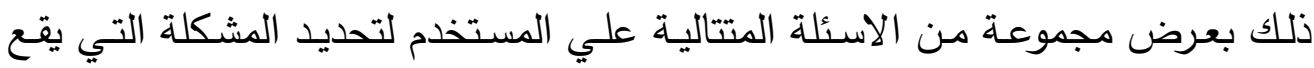

$$
\text { فيها، ولتشخيص أسباب المشكلة. }
$$

r. ثم ينتقل النظام الي المرحلة الثانية حيث يقوم النظام بتحديد الحل المناسب للمشكلة

$$
\text { ويقوم النظام الخبير التعليمي بعطلية شرحها. }
$$

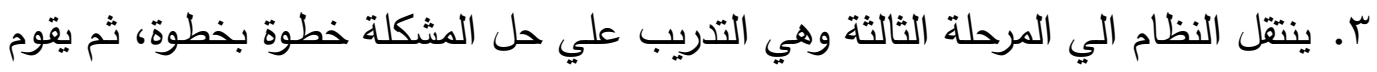
بعملية تشخيص له مرة أخري وهكذا يظل النظام يكرر مع المستخدم حتي يقوم يصل إلى مرحلة الاتقان فى حل الششكلة، وكذلك يسمح النظام الخبير للمستخدم بالأسئلة

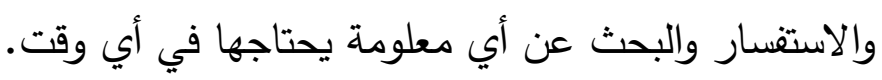
أي أن النظام الخبير يأخذ المستخدم في عدة مراحل ( تشخيص - شرح - تدريب ) وهكذا في هذا التسلسل حتي يصل بالمستخدم الي مرحلة اتقان حل المشكلة ويتخللها عمليات البحث عن معلومات اضافية والاستفسار عن كافة المعلومات.

\section{مثال لنظام خبير أثناء التشفيل وتطبيقه فى جودة المدارس :}

فيما يلي نظام خبير مبني علي القواعد ( Rule - Based ) يستخدم لتقديم استثارة عن طريق نظام الاختيار (Auto Select) لمساعدة المستخدم لايجاد حل لمشكلة التتييم الذاتي

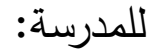
يقوم المستخدم بالاجابة عن الاسئلة باختيار رقم الاجابة الصحيحة: س ا : يتم التهيئة لنشر ثقافة الجودة في المدرسة من خلال:

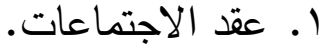




$$
\begin{aligned}
& \text { r. توزيع المطبوعات الورقية. } \\
& \text { با ب. لا أعرف. } \\
& \text { اجابة المستخدم رقم }
\end{aligned}
$$

س : يتم الاستعداد لنشر ثقافة التقييم الذاتي في المدرسة من خلال:

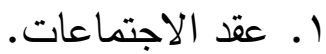

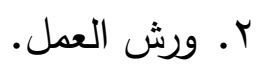

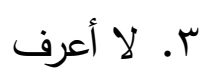

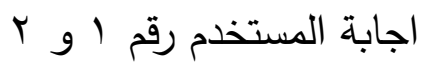

سب : يضم فريق التقييم الذاتي أعضاء إنه

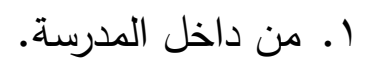

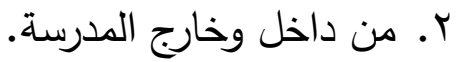

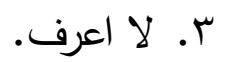

سؤال المستخدم لماذا؟ Why

1- اذا لم يشتمل فريق التقييم الذاتي علي بعض مجالس الأمناء.

$$
\text { [and] }
$$

r- ولم يتضمن فريق التقييم الذاتي علي بعض الطلاب.

$$
\text { [Then] عندئن }
$$

يجب اعادة تثكيل الفريق واشـراك هذه الفئات وذلك لأهميتها في أداء عملية التقييم الذاتي

$$
\begin{aligned}
& \text { للمدرسة. } \\
& \text { ويكرر السؤال } \\
& \text { سع : يضم فريق التقييم الذاتي أعضاء : } \\
& \text { 1- من داخل الددرسة. } \\
& \text { r- من داخل وخارج المدرسة. } \\
& \text { r- لا اعرف. } \\
& \text { اجابة المستخدم العزد }
\end{aligned}
$$




$$
\begin{aligned}
& \text { س 0: توزع بطاقات الأداء علي: } \\
& \text { 1 - الفئات المختلفة داخل وخارج المدرسة. } \\
& \text { ץ- الفئات المختلفة داخل المدرسة. } \\
& \text { r- ألا أعرف } \\
& \text { اجابة المستخدم رقم } \\
& \text { س \: استخدم فريق التقييم الذاتي أدوات جمع البيانات: } \\
& \text { 1 - المقابلة. } \\
& \text { r- الملاحظة. } \\
& \text { r- التصوير }
\end{aligned}
$$

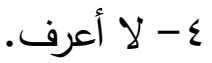

$$
\begin{aligned}
& \text { اجابة المستخدم رقم }
\end{aligned}
$$

يسمح النظام بالتغيير في الاختيارات قبل اتخاذ القرار وذلك بعرض الأسئلة والاجابات

$$
\text { علي المستخدم كالآتي: }
$$

ا- يتم التهيئة لنشر ثقافة الجودة في المدرسة من خلال عقد الاجتماعات. r- تم الاستعداد لنشر ثقافة التقييم الذاتي في المدرسة من خلال عقد الاجتماعات وورش للعمل. ب- يضم فريق التقييم الذاتي أعضاء من داخل المدرسة. ع- توزع بطاقات الأداء علي الفئات المختلفة داخل المدرسة. 0- استخدم فريق التقييم الذاتي أدوات جمع البيانات الملاحظة. ثم يقوم النظام الخبيز بتقديم التوصيات والمقترحات التي تحقق الاختيارات المحددة في الخطوة السابقة:

ا- يجب أن تضم عملية التهيئة لنشر ثقافة الجودة في المدرسة من خلال عقد الاجتماعات

$$
\text { وتوزيع مطبوعات ورقية. }
$$

r- يجب أن يضم فريق التقييم الذاتي أعضاء من داخل وخارج المدرسـة ممثلة في بعض

$$
\text { أعضاء مجالس الأمناء وبعض الطلاب. }
$$

$$
\text { r- يجب توزيع بطاقات الأداء علي الفئات المختلفة داخل وخارج المدرسة. }
$$

ع- يجب علي فريـق التقيـيم الذاتي عقد مقـابلات، وتصـوير عمل الفئات المختلفـة مـن

$$
\text { العاملين بالمدرسة. }
$$

